\title{
Stock Market Structure, \\ Volatility, and Volume
}

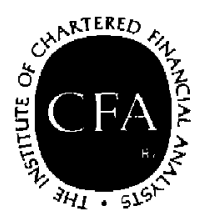

The Research Foundation of

The Institute of Chartered Financial Analysts 


\section{Stock Market Structure, Volatility, and Volume}


(C) 1990 The Research Foundation of the Institute of Chartered Financial Analysts

All rights reserved. No part of this publication may be reproduced, stored in a retrieval system, or transmitted, in any form or by any means, electronic, mechanical, photocopying, recording, or otherwise, without the prior written permission of the copyright holder.

This publication is designed to provide accurate and authoritative information in regard to the subject matter covered. It is sold with the understanding that the publisher is not engaged in rendering legal, accounting, or other professional service. If legal advice other expert assistance is required, the services of a competent professional should be sought.

From a Declaration of Principles jointly adopted by a Committee of the American Bar Association and a Committee of Publishers.

ISBN 10-digit: 0-943205-08-5 ISBN 13-digit: 978-0-943205-08-3

Printed in the United States of America

Joni L. Tomal, Editor

Nina D. Hutchinson, Typography/Layout

October 1990 


\section{Mission}

The mission of the Research Foundation is to identify, fund, and publish research material that:

- expands the body of relevant and useful knowledge available to practitioners;

- assists practitioners in understanding and applying this knowledge; and

- enhances the investment management community's effectiveness in serving clients.

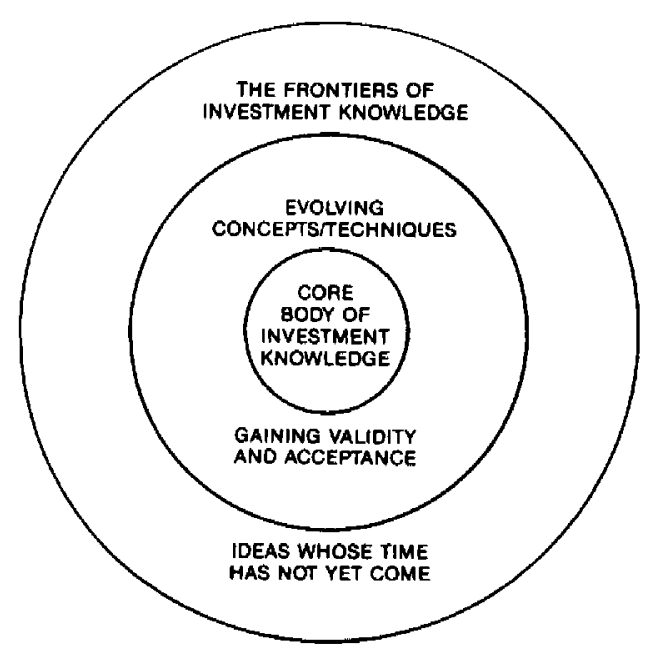

The Research Foundation of

The Institute of Chartered Financial Analysts

P.O. Box 3668

Charlottesville, Virginia 22903

(804) $977-6600$ 


\section{Table of Contents}

Acknowledgements $\ldots \ldots \ldots \ldots \ldots \ldots \ldots$. . . . . . .

Foreword $\ldots \ldots \ldots \ldots \ldots \ldots \ldots \ldots \ldots \ldots \ldots$

Introduction $\ldots \ldots \ldots \ldots \ldots \ldots \ldots \ldots \ldots$ xvii

Chapter 1. The Relation between Stock Market Structure and Volatility $\ldots \ldots \ldots \ldots \ldots \ldots$

Determinants of the Opening Price

Structural Volatility

Description of the Return Analysis

Separating Daytime and Overnight Volatility

Description of the Data

Chapter 2. Characteristics of Openings and Closings $\ldots \ldots 13$

Timing

Volume at the Opening

Day-of-the-Week Effects

Chapter 3. Return Volatility . . . . . . . . . . . . . . . . 21

Return Volatility at the Opening

Serial Dependence in Returns

Implied Bid-Ask Spreads

Daytime Versus Overnight Volatility

Day-of-the-Week Effects on Returns and Volatility

Chapter 4. Volatility and Volume . . . . . . . . . . . . . . . 39

Trading Volume and Price Volatility

Transaction Volume and Price Reversals

Chapter 5. Summary . . . . . . . . . . . . . . . 53

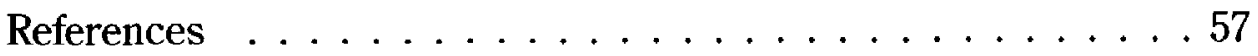




\section{ACKNOWLEDGEMENTS}

This research was supported by The Research Foundation of the Institute of Chartered Financial Analysts. Stoll acknowledges the additional support of the Financial Markets Research Center and the Dean's Fund for Faculty Research at the Owen Graduate School of Management, Vanderbilt University, and Whaley acknowledges the support of the Futures and Options Research Center and the Unisys Fund at the Fuqua School of Business, Duke University. Very capable computer work was provided by Athena Lee. We appreciate the helpful comments received when the paper was presented at Rutgers University, Vanderbilt University, the NBER Conference on Stock Market Volatility in Puerto Rico, and the "Imperfections in Financial Markets" conference at Minaki, Ontario. We also thank Fischer Black, Michael Brennan, Larry Fisher, F. Douglas Foster, Larry Harris, and Alan White. A portion of this paper, entitled "Market Structure and Volatility," was printed in the Spring 1990 issue of The Review of Financial Studies, and we acknowledge the helpful comments of an anonymous referee for that journal.

Hans R. Stoll

Owen Graduate School of Management

Vanderbilt University

Robert E. Whaley Fuqua School of Business

Duke University 


\section{FOREWORD}

The practical implications of this research are extensive. Markets open and close each day and are "out of business" for long periods over the weekend. The Dow Jones Industrial Average falls by $\mathrm{X}$ number of points and the authorities shut trading down, in effect creating intraday closings and openings. Then there is Friday's trade-on-close: Just before the market shuts down for the weekend, a single-shot, discreet auction takes place. And what about trusteed funds that trade on either the open or the close and are subject to "best execution" rules? Trying to analyze any of these real-world conditions reveals the chasm that exists between our evidential and our anecdotal knowledge of trading on opening or closing prices. Thanks to Stoll and Whaley, we now have the thorough analysis needed to peer into several facets of this long-standing mystery. My focus is on the implications of the study for trading practices. I will also address some policy issues. Along the way, however, I play loose with the findings at times so as to emphasize possibilities, not necessarily solutions.

Before beginning, let's refresh our memories regarding the nature of traders. Information traders are those who have valuable information and act on it. Because they have this information they need to trade quickly. True price is not a major consideration. Because private information is not likely to remain that way for long, immediacy is the issue of consequence. Immediacy is the need to trade "right away," almost regardless of the then-prevailing price.

Pseudo information traders are those who believe they have truly valuable information but do not. They create the noise in the trading mechanism, because their trades are not "reasonable." They trade primarily on generally available information, which, by definition, is not profitable because it is already reflected in market price. The costs of these transactions are great because no value is added to portfolios as a result of the trade, but the costs are incurred nonetheless. You and I cannot differentiate easily between an information trader and a pseudo one. That is what creates the noise. Liquidity traders trade to satisfy normal portfolio liquidity needs. ${ }^{1}$

\footnotetext{
${ }^{1}$ See Jack L. Treynor and Wayne H. Wagner, "Implementation of Portfolio Building: Execution," in John L. Maginn and Donald L. Tuttle, eds., Managing Investment Portfolios, $2 \mathrm{~d}$. ed. Charlottesville, Virginia: Association for Investment Management and Research.
} 
Now, given the seeming difficulty money managers have in outperforming the Standard \& Poor's 500 Index, more than one commentator has suggested that controlling trading costs is a way to improve results. As obvious as that seems, it is not so obvious that these controls are in place. Stoll and Whaley's study suggests some ways to think about controlling trading costs. Let's take a look at what happens on the opening and the close.

The finding that opening prices tend to be reversed indicates that suppliers of immediacy are extracting a premium for their services. This condition is inconsistent with an assumption of an informed trading presence. Informed traders ought to reverse all prices. The authors suggest that some component of price change is likely to be related to the presence of private information that is revealed through trading itself. Whatever the case may be, the question remains: Do we want to trade on the open given this empirical reality? If the reversals are not random, probably not. Fund managers that trade on the open may disadvantage portfolio performance.

The estimated range of bid-ask spreads ( 0.8280 to 0.6651 percent) implies that an opening price that deviates from the prior closing price will tend to reverse during the day. This phenomenon is consistent with the idea that specialists earn profits by trading at the opening and offsetting positions during the day. If they do and if trading is a zero-sum game, the losers are those who trade with the specialist on the open. To exacerbate matters, the average opening is 15 minutes later than the official opening for trading, and the price is set by a semi-monopolist specialist who equilibrates supply and demand as recorded on his book. Thus, the monopolist earns excess returns from his buyer client. In light of that finding, it is not a stretch of analysis to wonder why so many trades are executed on the openings or why the pricing of portfolios is based on the open or the close, primarily the latter. Putting aside the matter of whether the specialist system should be eliminated, at the minimum should the specialist be forced to show his book at the opening? Although this is a policy issue as well as a trading one, even under normal circumstances trading into the specialist's book is courting havoc. Doing so at the opening-when value-, noise-, and liquidity-based traders also transactcreates not uncertainty, but the almost certain result that the monopoly power of the specialist will prevail and trading costs to all others will be excessive.

Stoll and Whaley show us that opening price is more likely to reverse the price change of the preceding day if the volume on the prior day was above normal and if the opening volume is below normal. How many trading desks 
account for this? How many portfolio managers, for that matter, ask their traders about this kind of information, if they consult them at all?

Furthermore, this finding suggests that openings on high volume are less under the control of specialists than openings on low volume, a not-unexpected but necessary observation. So, is the specialist most needed when volume is low? Does the specialist assume greater monopoly power when volume is low? Ask yourself this: Should professionals trade into high-volume or into lowvolume markets? What seems to be the current practice?

Another interesting finding is that opening share volume-the number of shares traded in the first transaction-is slightly more than four times normal on average, and even greater for the largest stocks. For low-volume stocks, the time to open is almost two times later than normal, which, as noted, averages fifteen minutes after the opening bell. In other words, opening volume is far greater for large stocks than it is for small ones, and they tend to open sooner. Those who buy and sell small stocks should try to determine the impact on trading costs of these "delayed" first trades. If the lagged opening allows one to include more information before the trade takes place, the time gap may be valuable. That event is doubtful, however, because information for this short period is (1) not likely to be meaningful, and (2) may average to zero if it comes randomly, as some studies have suggested.

The authors' discoveries about volatility itself are important. The sources of volatility are noise, as exhibited by reversals at the opening, and private-information trading, as exhibited in the correlation between volume and volatility, as well as the positive correlation of volume with the close. The volatility associated with the presence of private information that is revealed by the trading process itself, or from fortuitous nonsynchronous liquidity trading, creates price-pressure impacts and enables the suppliers of immediacy to earn excess revenues. Again, we are back to the specialist, who is probably the primary supplier of immediacy. Given the large blocks in which they trade, institutions may become temporary specialists and suppliers of immediacy. This is especially the case when making a portfolio adjustment, such as is occasioned by rebalancing. This would tend to capture some of the profits and reduce trading costs.

The authors find that daytime volatility is slightly more than five times as large as overnight volatility, but that weekend volatility is only 28 percent greater. The likely explanations for this are that (1) more public information is released during weekdays than at night or over weekends; (2) information 
may be revealed through trading when the market is open; and (3) liquidity traders create noise to which the suppliers of immediacy respond. We may have suspected as much; Stoll and Whaley document it. But have we built this information into our trading systems?

Technicians may take some comfort in knowing that high volume tends to be associated with price continuations. An overnight return based on high opening volume is likely to be of the same sign as the preceding day's daytime return; that is, a trend is set in motion. Moreover, an overnight return on high opening volume tends not to be reversed during the rest of the day if the volume during the rest of the day continues above normal. The trend continues. The study does not suggest whether one can trade profitably on such information; that was not its purpose. Other studies tell us, however, that it is not likely to be an exploitable phenomenon.

The connection between volume and return volatility is intriguing. High volume alone at the opening tends to accentuate overnight return volatility. High volume during the rest of the day accentuates daytime return volatility. The authors take this result to imply that volume has a permanent effect on prices and, in turn, to imply that private information is revealed through trading, a position typically taken by technicians. For stocks with high volume, delayed openings tend to accentuate overnight return volatility, even though volatility during the rest of the day is not greater than normal. This suggests that the price determined in delayed openings is a true price even though the returns are more volatile. For stocks with low volume, a delay in opening means that volume is less than normal, and daytime volatility is lower the longer the time until the first transaction.

Negative returns are present from the Friday close to the Monday open as well as on Mondays themselves. Average returns on all trading days are largest on Friday. This finding is consistent with the weight of prior studies but not with the efficient markets hypothesis. Whereas differences in returns across days of the week are not sufficiently large to arbitrage, a practical implication of the findings is to delay purchases until Monday and to make sales at the close on Friday.

Turning now to capital market regulation, we find that Stoll and Whaley provide insights that are needed for such major policy issues. For example, the utility of "circuit breakers" is unknown. As of this writing (August 1990), with Mideast unrest at full force, the Dow Jones Industrial Average stood at about 2483 . It was at 2810 on the first trading day of 1990 , rose to 2999.76 on 
July 17,1990 , an increase of 6.75 percent, and stood at 2645 one month later, a decline of 11.82 percent. The decline from the first of the year was 11.65 percent; from the high, 17.23 percent. During the year, circuit breakers were invoked seven times, presumably to mitigate volatility. We will never know for sure whether they did the intended job, but it looks like volatility is flat, or lower. Based on Stoll and Whaley's data, the estimated annual daily standard deviation of returns is 15.1 percent, which compares with the average annualized standard deviation of 15.5 percent for the decade of the $1980 \mathrm{~s}$. So the numbers are in line, thus far-yet, few who participate in the "Iraqi" market would think it was less volatile than at other times.

While it remains to be seen whether circuit breakers are needed at all, if they are, Stoll and Whaley's transaction shock concept should be part of the analytical framework that determines a sensible and useful way to approach them. The shock occurs when the combination of excess demand, the costs of maintaining the specialist's inventories, and the specialist's monopoly power combine at the opening. It represents the net effect of information trading, liquidity trading, and the specialist's response to excess demand. When shocks occur-as in October 1987-what is the smart reaction? One choice is to do nothing, which implies that market participants will rectify matters in due course, usually within minutes. This let-nature-take-its-course approach has much to commend it, particularly because it lets market participants exercise their judgments freely.

But what about invoking some sort of regulation? If so, what form should it take? What is the model for regulation? Is it to emulate what a rational set of investors, temporarily irrational (according to someone else's judgment), would do? One would hope so. The presumption, however, is that regulation will be better than the collective wisdom of market participants. Assuming for the moment the desirability of regulation, a concession not easily made, what form should it take? Are circuit breakers the answer? What if circuit breakers introduce more volatility, rather than dampen it? The Stoll and Whaley data, the most extant ever, suggest they might. If opening prices are more volatile than at other times during the day, as noted previously, and if more closings by means of circuit breakers introduce more openings, the market mechanism itself might then have an effect opposite of regulatory intent: It might just increase volatility.

The study's focus on opening prices enhances our understanding of the impact of the type of auction, discreet versus continuous, that ought to be at 
work when a regulatory mechanism such as circuit breakers is called on. If opening prices after a trading suspension tend to be more volatile, circuit breakers may well be counterproductive. Stoll and Whaley find that volatility is greater at the opening than at other times under normal conditions, but especially so when a transaction shock occurs. Such discreet auctions-oneshot market openings within market openings-do not seem to mitigate volatility. Countervailing this view is their finding that prices around the open, but not around the close, tend to reverse. Thus, a case for circuit breakers could be made.

Another regulatory aspect that emerges from studies of the trading mechanism concerns the specialist, everyone's favorite whipping boy. The authors' approach to the role of the specialist is inferential only. Their study is novel, appealing, and applicable because they use prices determined at the opening (which are the result of a noncontinuous auction) rather than prices at the close (the result of trading activity taking place more or less continuously during the day). Where does the specialist fit in such a market structure? Opening prices are intriguing to all of us because it is then that the specialist sees the cumulative order book, the orders submitted by traders during the overnight or weekend period of market closure. At the opening the specialist conducts a single auction in order to equilibrate demand and supply-to clear his books of accumulated market orders. By contrast, later in the day the specialist does not know whether a particular order will be followed by others on the same side. Does society have an interest in the monopoly profits that the specialist seems to earn on opening trades? Or pension plan beneficiaries?

Is this the end to the story? One hates to say it, because we have heard it over and over again, but more studies are needed. Even so, we have learned a great deal from this study and perhaps the point is near when some rules can be based upon it. Prudence suggests, however, that there is a point at which studies stop and wisdom takes over. Philosophers tell us that wise decisions surface when persons of good will and common goals meet, debate, and reconcile. Capital markets, and society's commonweal, need such collective wisdom.

Charles A. D'Ambrosio, CFA Research Director Research Foundation of the ICFA 


\section{INTRODUCTION}

The stock market crash of 1987 prompted intense focus on the effect of market structure on the behavior of securities prices. A number of policy recommendations were proposed as a result of the crash, including trading halts, the elimination of program trading, and trading bans on derivative instruments. ${ }^{1}$ One suggestion is already in place, namely circuit breakers to halt trading if markets become excessively disrupted. A trading halt is only reasonable, however, if the procedure for reopening trading leads to prices that more closely reflect the true value of securities. In this study, the procedure for opening stocks on the New York Stock Exchange (NYSE) is examined. The opening of trading on the NYSE provides an excellent experiment for investigating the effect of a particular market structure on price volatility. ${ }^{2}$

This study is organized as follows. In Chapter 1, the structural factors affecting price volatility are discussed. In particular, opening transactions on the NYSE are described and contrasted with transactions there during the rest of the trading day. We develop a simple model of stock returns that partitions return volatility into a component attributable to new information and a component attributable to trading shocks. Chapter 1 also contains a description of the data used in our empirical analysis-daily opening and closing prices and volumes for all transactions in NYSE common stocks for the years 1982 through 1986. This sample of information is perhaps the most comprehensive used in any market-structure study to date.

Chapter 2 presents descriptive statistics on the timing of, and trading volume at, the opening and closing transactions of the day.

In Chapter 3, the ratio of the return variance calculated from open-to-open returns to the return variance calculated from close-to-close returns is computed for each stock in each month during the five-year sample period. The average variance ratio exceeds one, which suggests that volatility at the open exceeds volatility at the close. The serial dependence of returns around the open and around the close is used to infer the extent to which the cost of supplying immediacy is a source of volatility. We investigate the relative magnitudes of daytime versus overnight return volatility and present evidence

${ }^{1}$ For an analysis of policy issues arising from the crash, see Stoll and Whaley (1988).

${ }^{2}$ See the References (pp. 57-60) for a list of market-structure research studies. 
on how volatility, average returns, and serial covariances of returns vary by day of the week.

In Chapter 4, we examine how volatility of returns and serial dependence in returns are related to trading shocks. In addition, we test whether the volatility associated with trading shocks is a result of higher compensation of the specialist or of greater trading activity by informed traders.

Our summary is presented in Chapter 5. 


\section{The Relation between Stock Market Structure and Volatility}

The opening of trading on the NYSE provides an excellent experiment for investigating the effect of a particular market structure on price volatility. In this chapter, we describe the determinants of the opening price, present a simple model of stock returns that is used to test the relation between market structure and volatility, and describe the data used in the study.

\section{Determinants of the Opening Price}

The opening on the NYSE has many of the characteristics of a call-auction market. All market orders that have accumulated overnight, limit orders to buy at or above the opening price, and limit orders to sell at or below the opening price are executed at a single price- the opening price. The role of the specialist is important. The specialist is the auctioneer who accumulates orders and determines the opening price with the assistance of the Opening Automated Reporting System (OARS). Thus, most of the trades at the open are directly between and among investors, although the specialist may participate at the open to offset order imbalances. During the rest of the day, orders are executed in the sequence in which they arrive. Except for block transactions, which are prearranged in upstairs trading rooms, intraday trading usually requires the participation of the specialist on one side of the transaction. ${ }^{1}$

${ }^{1}$ Stoll (1985) estimates that the specialist participates in 90 percent of the nonblock shares traded on the NYSE as either dealer for his own account or broker for the limit-order book. 
The specialist's participation at the open makes price determination different from the classic auction in which a disinterested auctioneer determines the market clearing price. ${ }^{2}$ The specialist has the opportunity to trade for his own account as a dealer when he observes an order imbalance. If the specialist's role as dealer is important at the open, price patterns around the open should be like price patterns around other transactions in which the specialist acts as dealer. In other words, the price patterns around the open should exhibit the price reversals normally observed in dealer markets as prices move between bid and ask levels. On the other hand, if the open is a classic auction in which all investors may participate, imbalances will be zero, and the opening price will more closely reflect the true price of the security.

The price-determination process at the open may be illustrated using the demand-supply framework illustrated in Figure 1 . The excess demand curve is the kinked line $D D$. The vertical line reflects the excess demand of public market orders to buy over public market orders to sell. The imbalance of market orders (at any price) is $Q_{m t}$. The downward-sloping segment is the excess demand of limit orders to buy over limit orders to sell. The price of the stock implied by the current public information set, which we refer to as the true price, is $P_{t}^{*}$. The total imbalance at the true price $P_{t}^{*}$ is $Q_{t}^{*}$.

In a perfectly functioning auction market with a disinterested auctioneer, the imbalance shown in Figure 1 causes a trial clearing price above $P_{t}^{*}$ to be announced and new orders to be solicited. New prices are called out until a new true price, at which the imbalance is zero and no trader wishes to revise his order, is determined. To the extent that imbalances convey information, the true price might change during the auction.

Openings on the NYSE do not follow such a procedure. Instead, when the specialist observes an imbalance, he may offset it on his own account. His only requirement is that he must execute all market orders. Figure 1 illustrates how the opening price would be determined under this procedure. Line $S$ is the specialist's supply function. It reflects the costs of supplying immediacy (e.g., inventory holding costs and transaction costs) incurred by the specialist

\footnotetext{
${ }^{2}$ In a classic auction market, investors submit orders that are cleared without the participation of the auctioneer. Orders are contingent on the clearing price either explicitly in the sense that a demand schedule is submitted by investors, or implicitly in the sense that investors are allowed to revise orders on the basis of tentative clearing prices announced by the auctioneer.
} 


\section{FIGURE 1}

\section{Excess Demand at the Opening $(D D)$, Marginal Revenue $\left(D D^{\prime}\right)$, and Specialist Supply of Shares $(S)$}

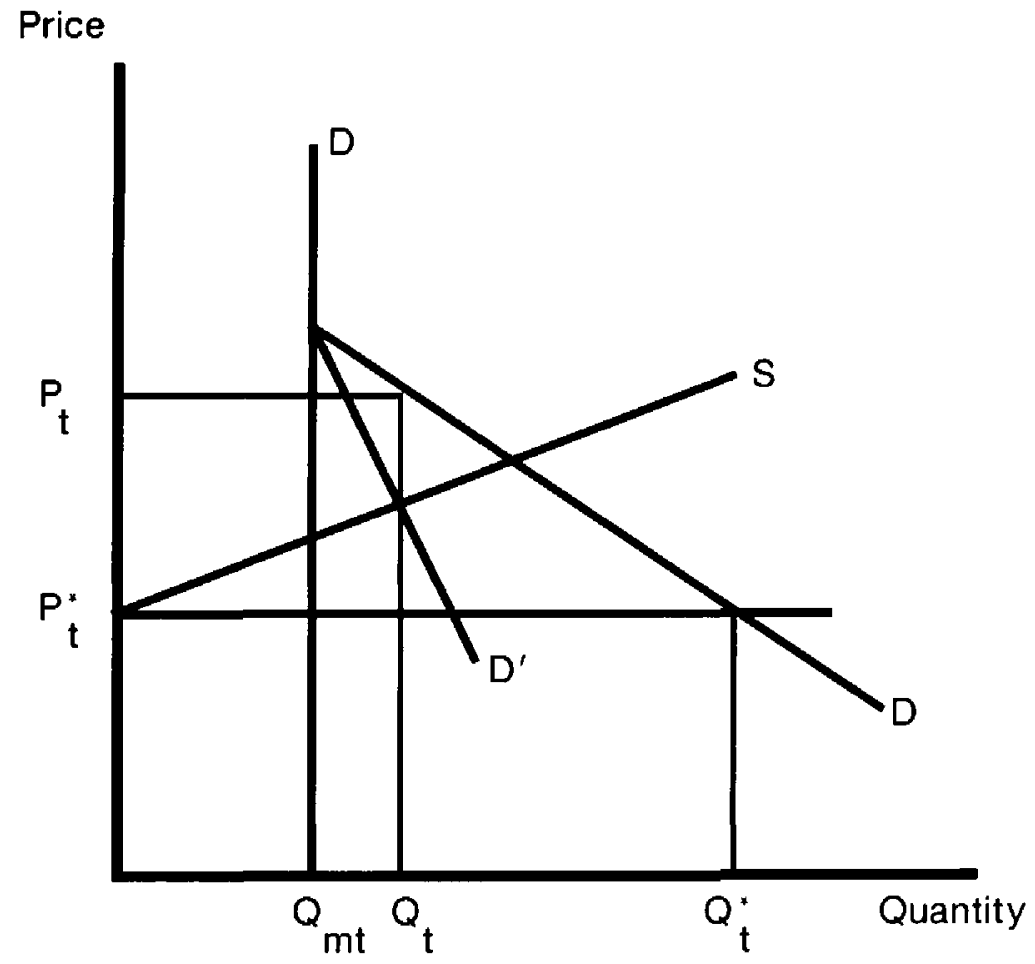

and other traders. Immediacy, remember, is the service of taking an offsetting position to enable other traders to trade immediately. ${ }^{3}$ If the specialist is a monopolist at the open, he prices off the marginal demand curve, $D D^{\prime}$, to set an opening price $P_{t}$, and sells $Q_{t}$ shares for his own account.

The specialist's problem at other times of the day is quite similar to that at the open, but there is a difference. At the open the specialist can see the imbalance, and he has information about who is trading before he must decide the price at which he will trade. During the rest of the day, the specialist posts

${ }^{3}$ Demsetz (1968) first described the dealer's role as providing immediacy in the marketplace. Stoll (1978) provides a model of the dealer's cost function. 
bid and ask prices without knowing the size of the next trade, who the trader will be, or whether it will be a purchase or sale. ${ }^{4}$

\section{Structural Volatility}

The volatility of security prices is important. ${ }^{5}$ Most volatility is fundamental in the sense that it is related to underlying economic uncertainties, but some volatility may be related to the structure of trading arrangements. This latter source of volatility is the focus of this study. Volatility of prices is caused by new public information, trading pressures of investors, and the manner in which immediacy is supplied to offset these trading pressures. In terms of Figure 1, public information changes $P_{t}^{*}$ without causing excess demand because all investors shift their demands to reflect the new information. The analysis in this study abstracts from the effect of information on volatility and focuses on trading pressures and market structure.

Trading pressures arise from information traders, who trade on the basis of private information, and from liquidity traders, who trade because of cashflow needs. The noise introduced by liquidity traders allows information traders to disguise themselves and capitalize on their information. Suppliers of immediacy lose to information traders and profit from liquidity traders. ${ }^{6}$ The ability of information traders to disguise themselves and the cost of supplying immediacy depends on market structure. We examine the effectiveness of opening procedures in dealing with trading pressures and providing immediacy.

Some structural arrangements contribute to increased volatility of prices at the open; others contribute to decreased volatility at the open. Two structural factors that contribute to increased price volatility at the open are (1) lack of disclosure and inability to revise orders, and (2) specialist monopoly power.

\footnotetext{
${ }^{4}$ In principle, the specialist can set bid and ask prices that take into account any contingency (transaction size, trader identification, etc.); in practice, however, this is impossible. As a result, the ex post pricing made possible by opening procedures offers considerable advantage over the ex ante procedure required during the rest of the day.

${ }^{5}$ Volatility affects the public's confidence in securities markets and ultimately the level of saving and investment in the economy.

${ }^{6}$ The interaction between information and liquidity traders was first discussed in Bagehot (1971). More recent studies include Kyle (1985), Easley and O'Hara (1987), Admati and Pfleiderer (1988), and Foster and Viswanathan (1990). For a model of volume and volatility in the presence of information and liquidity traders, see Chopra (1990).
} 
Lack of disclosure and inability to revise orders. If imbalances prior to the opening are not publicly disclosed, traders (other than the specialist) cannot assess the probable price change and, hence, the desirability of placing an opening order or of revising an existing order. ${ }^{7}$ As a result, imbalances and price changes may be larger than they should be. Unless the orders submitted by traders are very complex, a one-shot auction such as the specialist provides cannot result in a price with which all traders are satisfied. A one-shot auction may also induce trading strategies that increase volatility. For example, to avoid being rationed out, investors might place larger orders than they would otherwise. $^{8}$

Specialist monopoly power. In principle, the specialist may offset an imbalance and limit the price effect; he has no incentive to do so, however. Instead, as Figure 1 illustrates, the specialist has an incentive to induce a price effect that compensates him for the service of immediacy and produces a monopoly profit.

On the other hand, several structural factors can contribute to decreased volatility at the open: (1) disclosure requirements, (2) oversight, and (3) the crowd.

Disclosure requirements. Opening-price volatility may be reduced if imbalances are disclosed and investors are given the opportunity to revise orders before an opening price is determined. Full disclosure and sufficient opportunity to revise orders could totally eliminate sources of instability arising from the structure of trading arrangements. Under current rules, a certain amount of disclosure is required and order revision is sometimes allowed. For example, if the specialist plans to change the opening price by more than a specified amount from the preceding day's close, he is required to disclose the likely opening-price change to dealers in other markets. Also, if the order imbalance is too large for the specialist to meet at reasonable prices, the specialist sometimes delays the opening. In such cases, the specialist communicates the magnitude of the imbalance to the crowd and solicits additional orders.

\footnotetext{
${ }^{7}$ The ability to revise orders can lead to gaming as traders submit fake orders that they later rescind. To limit this behavior, revisions might be subject to a fee or limited to price improvements (i.e., purchases at higher prices or sales at lower prices).
}

${ }^{8}$ See Ho, Schwartz, and Whitcomb (1985). 
Oversight. The specialist is subject to general regulatory oversight, and the quality of his markets is evaluated by the exchange. In delayed openings, the specialist is subject to direct oversight from a floor governor.

The crowd. Floor traders at the specialist post ("the crowd"), competing with the specialist, could limit the extent to which order imbalances push the opening price away from the true equilibrium price. Under current procedures, the crowd competes directly at the open only if the specialist discloses the opening imbalance. The crowd competes indirectly by policing the opening and standing ready to trade with the public immediately after the opening.

The above arguments about volatility at the open lead to the following two competing hypotheses:

$H_{0}$ : Structural price volatility at the open is less than at other times of the day. This result is expected if the opening procedure follows a classic auction market. In such a market, the opening price would fall between the bid and ask prices set by the specialist.

$H_{A}$ : Structural price volatility at the open is greater than at other times of the day. This result is expected in a one-shot auction in which the specialist has greater monopoly power than at other times of the day and establishes prices that vary by more than the normal bid-ask spread.

\section{Description of the Return Analysis}

In this section, we specify how volatility is measured and how it may be partitioned into components to evaluate the merits of these competing arguments. The first step is to define the framework outlined in Figure 1 in terms of returns. The second step is to isolate the effects of trading shocks, bid-ask spreads, and daytime versus overnight volatility.

The framework of Figure 1 may be restated in terms of stock returns. In Figure $1, P_{t}^{*}$ represents the true price of the security at time $t$, and $P_{t}$ represents the transaction price. Deviation of the transaction price, $P_{t}$, from the true price, $P_{t}^{*}$, reflects the net effect of the public's excess demand and the specialist's costs and monopoly power, defined as the transaction shock. This transaction shock may be stated as a proportion of stock price, so that the transaction price is

$$
P_{t}=P_{t}^{*} U_{t}
$$


where $U_{t}$ is the transaction shock. That is, the transaction price depends on the true, but unknown, price plus an adjustment for the combined effect of excess demand and the specialist's lists and monopoly power.

This relation may be restated in terms of logarithmic rates of return,

$$
r_{t}=e_{t}+\left(u_{t}-u_{t-1}\right)
$$

where

$$
\begin{aligned}
& r_{t}=\ln P_{t}-\ln P_{t-1}, \\
& e_{t}=\ln P_{t}^{*}-\ln P_{t-1}^{*}, \text { and } \\
& u_{t}=\ln U_{t} .
\end{aligned}
$$

The variable $e_{t}$ reflects new public information that changes the security's true price. Markets are assumed to be informationally efficient so that $e_{t}$ is serially independent. ${ }^{9}$ The price shock, $u_{t}$, reflects the structural factors of interest. The price shock may reflect a trading imbalance caused by the demands or supplies of traders with private information, trading imbalances caused by the fortuitous nonsynchronization in the arrival of liquidity traders, or a higher fee charged by suppliers of liquidity, such as specialists. In other words, the price shock, $u_{t}$, represents the net effect of information trading, liquidity trading, and the specialist's response.

Using the return relation in equation (2), the variance of observed return may be written

$$
\sigma^{2}\left(r_{t}\right)=\sigma^{2}\left(e_{t}\right)+\sigma^{2}\left(u_{t}-u_{t-1}\right)+2 \operatorname{cov}\left(e_{t}, u_{t}-u_{t-1}\right),
$$

where $u_{t}$ is the transaction shock at time $t$, and $e_{t}$ is the information that arrives at times up to and including time $t$. The second term in equation (3) is the effect of trading shocks independent of a contemporaneous information shock, and the third term is the effect of any interaction between trading shocks and information. In a well-functioning opening auction, the disclosure of imbalances and trial market clearings would keep the volatility attributable to these factors [i.e., $\sigma^{2}\left(u_{t}-u_{t-1}\right)$ and $\operatorname{cov}\left(e_{t}, u_{t}-u_{t-1}\right)$ ] to a minimum, and the

\footnotetext{
${ }^{9}$ Serial dependence in returns is not necessarily inconsistent with efficiency because expected returns may be conditional on factors that are serially dependent. Over the very short time horizon used in this analysis, however, such serial dependence is hard to imagine.
} 
observed return volatility would be largely attributable to the volatility induced by new public information [i.e., $\sigma^{2}\left(e_{t}\right)$ ]. Trading shocks arising from liquidity traders would tend to be diversified away. To the extent any aggregate trading shock remained, a well-functioning auction market would provide a mechanism for attracting additional offsetting orders. Trading shocks arising from information trading would tend to be eliminated as the disclosure of imbalances revealed private information to the entire market.

\section{Isolating Trading Shock Effects}

To assess the magnitude of the volatility at the open, a volatility benchmark is needed. Volatility may be studied on returns spanning any 24-hour period beginning at a time other than the opening. We chose to look at closing prices for two reasons. First, with the exception of the open, market activity tends to be greatest at the close. Second, volatility calculations in the published literature are almost always based on closing prices. ${ }^{10}$

To isolate the influence of trading shocks from the influence of new public information, the variance-of-return relation in equation (3) is used to represent the variance of the open-to-open return, $\sigma^{2}\left(r_{o, t}\right)$, and to represent the variance of the close-to-close return, $\sigma^{2}\left(r_{c, t}\right)$. The ratio of the variances may be written

$$
\frac{\sigma^{2}\left(r_{o, t}\right)}{\sigma^{2}\left(r_{c, t}\right)}=\frac{\sigma^{2}\left(e_{o, t}\right)+\sigma^{2}\left(u_{o, t}-u_{o, t-1)}+2 \operatorname{cov}\left(e_{o, t}, u_{o, t}-u_{o, t-1}\right)\right.}{\sigma^{2}\left(e_{c, t}\right)+\sigma^{2}\left(u_{c, t}-u_{c, t-1}\right)+2 \operatorname{cov}\left(e_{c, t}, u_{c, t}-u_{c, t-1}\right)},
$$

where $u_{o, t}\left(u_{c, t}\right)$ is the transaction shock at the open (close) on day $t$, and $e_{o, t}$ $\left(e_{c, t}\right)$ is the information that arrives after the open (close) on day $t-1$ and on or before the open (close) on day $t$. Over a long time series, the variance of the new information variable based on opening prices equals the variance based on closing prices [i.e., $\left.\sigma^{2}\left(e_{o, t}\right)=\sigma^{2}\left(e_{c, t}\right)\right]$. Therefore, a variance ratio different from one must be caused by differences in the magnitudes of the second and third terms in the numerator and denominator of equation (4), respectivelythat is, trading shocks at the open vis-a-vis the close.

\footnotetext{
${ }^{10} \mathrm{An}$ exception to this statement is a study by Richardson and Smith (1988) that analyzes the volatility and serial correlation of hourly prices for the 30 Dow Jones Industrial Average stocks.
} 


\section{Isolating Bid-Ask Effects}

The covariance of returns across different time periods can be used to deduce whether the cost of immediacy imposed by the specialist is a source of volatility at the opening. During the trading day, negative serial dependence in returns is caused by movement between bid- and ask-price levels, as shown in Roll (1984) and Stoll (1989). Although no bid-ask spread exists at the open, a similar transaction cost is imposed when the specialist backs away from active orders. The implied spread at the open vis-à-vis the implied spread at the close should therefore reflect the difference in the cost of immediacy at the two different points in the day. ${ }^{11}$

Open-to-open and close-to-close returns may be partitioned into daytime and overnight returns in order to gain additional insight into return volatility. The logarithmic open-to-open returns may be expressed as the sum of the overnight return, $r_{n, t}$, and the return during the preceding day, $r_{d, t-1,}$

$$
r_{o, t} \equiv r_{d, t-1}+r_{n, t}
$$

and the logarithmic close-to-close return may be expressed as the sum of the overnight return, $r_{n, t}$, and the return of the following day, $r_{d, t,}$

$$
r_{c, t} \equiv r_{n, t}+r_{d, t}
$$

(See Figure 2.) Using these return definitions, the variance ratio may be written

$$
\frac{\sigma^{2}\left(r_{0, t}\right)}{\sigma^{2}\left(r_{c, t}\right)}=\frac{\sigma^{2}\left(r_{d, t-1}\right)+\sigma^{2}\left(r_{n, t}\right)+2 \operatorname{cov}\left(r_{d, t-1}, r_{n, t}\right)}{\sigma^{2}\left(r_{d, t}\right)+\sigma^{2}\left(r_{n, t}\right)+2 \operatorname{cov}\left(r_{d, t}, r_{n, t}\right)}
$$

Over a long time series, $\sigma^{2}\left(r_{d, t-1}\right)=\sigma^{2}\left(r_{t, t}\right)$, so the sum of the first and second terms in the numerator is approximately the same as the sum of the first and second terms in the denominator. A variance ratio $\sigma^{2}\left(r_{\theta, t}\right) / \sigma^{2}\left(r_{c, t}\right)$ different

\footnotetext{
${ }^{11}$ If the volatility is induced by traders with private information rather than by suppliers of immediacy, the serial covariance in returns will be zero. Glosten and Harris (1988), Stoll (1989), and Hasbrouck (1988) distinguish empirically between these two sources of volatility. Positive serial dependence implies a lagged adjustment of market prices to information, as in Goldman and Beja (1979) and Hasbrouck and Ho (1987).
} 


\section{FIGURE 2}

\section{Intervals over Which Returns are Calculated}

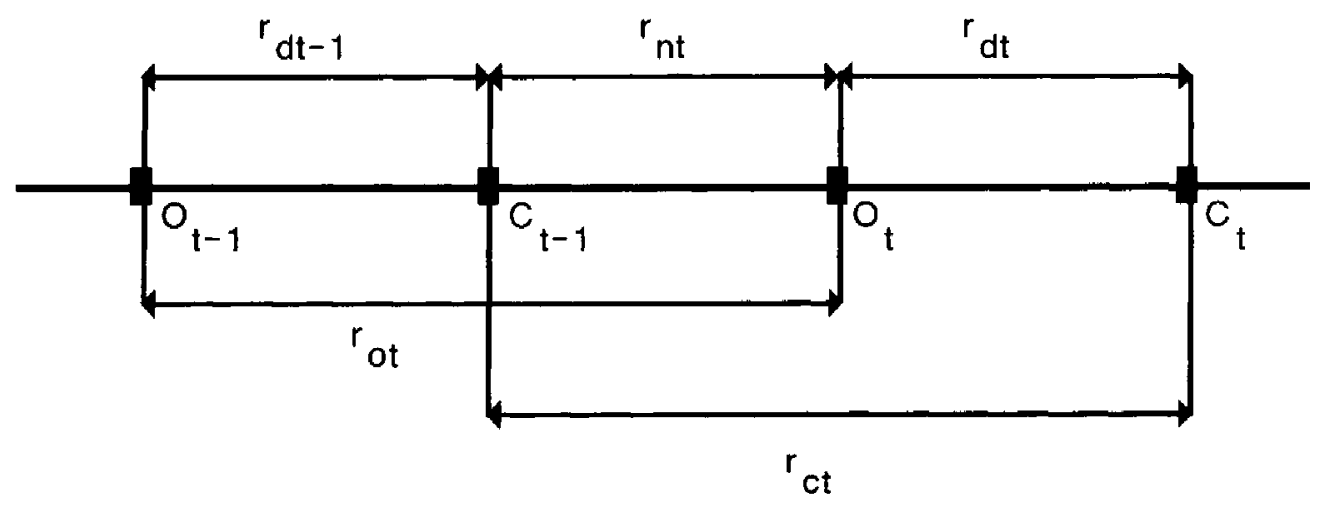

$$
\begin{aligned}
& \mathrm{O}_{t}=\text { Opening price on day } t \\
& \mathrm{C}_{t}=\text { Closing price on day } t .
\end{aligned}
$$

from one implies that $\operatorname{cov}\left(r_{d, t-1}, r_{n, t}\right)$ and $\operatorname{cov}\left(r_{n, t}, r_{d, t}\right)$ are not equal. A variance ratio greater than one, for example, implies $\operatorname{cov}\left(r_{d, t-1}, r_{n, t}\right)>\operatorname{cov}\left(r_{n, t}, r_{d, t}\right)$. The relative magnitude of the serial covariance expressions are important in understanding why ratio (5) is different from one.

The signs and the magnitudes of the serial covariance in equation (5) and the serial covariances of open-to-open and close-to-close returns provide evidence on the extent to which the specialist's cost of providing immediacy induces volatility at the open. For the specialist to earn income, prices must reverse (that is, rise after the specialist buys and fall after the specialist sells), which implies negative covariance.

\section{Separating Daytime and Overnight Volatility}

The computation of daytime and overnight returns allows us to investigate directly whether volatility is different in periods when the market is open than when the market is closed. Because the market is closed for 18 hours and is open for 6 , it seems reasonable to expect overnight volatility to be about three times higher than daytime volatility. We are also able to determine if daytime 
or overnight volatility varies by day of the week and whether implied bid-ask spreads are larger on certain days. The results of these tests are discussed in Chapter 3.

\section{Description of the Data}

The sample used in this study is the most comprehensive of any published market microstructure study to date. The data source is the Francis Emory Fitch, Inc. transaction file. It contains time-stamped records of all transactions on the New York Stock Exchange. From the Fitch file, the following daily information was compiled for each NYSE common stock during the five-year period 1982 through 1986: the time, price, and volume of the opening transaction; ${ }^{12}$ the time, price, and volume of the closing transaction; ${ }^{13}$ and the total share volume for the day. The Center for Research in Securities Prices (CRSP) daily master file was used to adjust for cash dividends, stock splits, and stock dividends in calculating returns from the Fitch price data.

Four exclusionary criteria were applied: (1) a stock was eliminated from the sample for the entire year if it traded on fewer than 100 days during the year; (2) a stock was eliminated if it traded at a share price of less than $\$ 3.00$ at any time during the year; (3) a stock was eliminated from the sample in a particular month if it had fewer than 15 price observations during the month, and (4) a stock was eliminated if it experienced any daily return in the month greater than 50 percent or less than -50 percent.

${ }^{12}$ The Fitch data report transaction times by minute. The opening volume is defined as the sum of all shares traded at the opening price and during the minute of the opening. Sometimes more than one opening transaction record appears on the Fitch tape.

${ }^{13}$ The closing volume is defined as the number of shares traded in the last transaction. 


\section{Characteristics of Openings and Closings}

Relatively little is known about the characteristics of the opening and the closing transactions of the day. Accordingly, we report the distribution of the times until the first transaction in individual stocks and the distribution of the times between the final transactions in individual stocks and the closing of the exchange. We also present evidence on the proportion of daily trading occurring at the opening transaction.

\section{Timing}

Descriptive statistics on the timing of opening and closing transactions are contained in Table 1. It is interesting to note that considerable time elapses before stocks actually begin trading. In 1986, for example, the average number of minutes between the official opening of the exchange and the opening transaction in a stock was 15.48 minutes. It is also interesting to note that trading typically stops well before the exchange closes. In 1986 an average of 19.94 minutes elapsed between the last trade and the close of the market. Between 1982 and 1986, the average time to open declined by 5.27 minutes, and the average time from the last trade to the close declined by 9.01 minutes. Both of these changes reflect, in part, the increase in stock market activity from the beginning to the end of the sample period.

The average number of minutes between the opening and the first transaction is related to the average volume of trading of the individual stocks. In Table 1, stocks are ranked within each month by average daily dollar trading volume in the month and clustered into deciles, containing approximately 140 stocks each, during each month of the sample period. In 1986, for example, 


\section{TABLE 1}

\section{Time to Opening and Time between Last Trade and Market Close*}

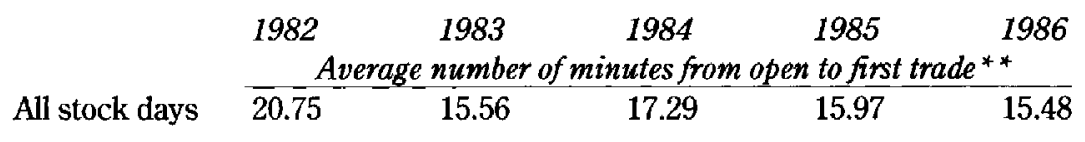

By daily dollar volume decile

Smallest
2
3
4
5
6
7
8
9

Largest

$\begin{array}{rr}82.91 & 62.34 \\ 35.37 & 23.37 \\ 21.99 & 14.92 \\ 15.40 & 10.86 \\ 11.58 & 9.13 \\ 9.30 & 7.92 \\ 8.02 & 7.06 \\ 7.23 & 6.46 \\ 6.85 & 6.31 \\ 8.79 & 7.23\end{array}$

70.34
28.25
18.64
13.41
10.46
8.54
6.93
5.77
5.09
5.44

68.59

67.40

23.37

14.92

10.86

9.13

7.92

7.06

6.46

7.23

5.44

26.49

16.32

11,89

25.78

16.09

11.49

9.28

8.77

7.24

6.71

5.46

4.45

5.85

4.15

4.41

4.98

All stock days

$\frac{A v}{28.95}$

Averag

\subsection{0}

26.55

4.98

By daily dollar volume decile

Smallest
2
3
4
5
6
7
8
9
Largest

$\begin{array}{rr}103.07 & 87.51 \\ 54.76 & 42.49 \\ 38.13 & 29.38 \\ 27.88 & 22.15 \\ 20.66 & 16.90 \\ 15.64 & 13.25 \\ 12.25 & 10.18 \\ 8.98 & 7.43 \\ 5.68 & 4.80 \\ 2.46 & 1.91\end{array}$

90.20
47.71
34.39
26.07
20.46
15.88
12.22
8.96
5.49
2.08

84.91

83.71

41.68

38.30

$28.63 \quad 25.08$

$21.25 \quad 17.56$

$15.99 \quad 12.79$

$12,23 \quad 9.14$

$8.82 \quad 6.39$

$\begin{array}{ll}6.05 & 4.02\end{array}$

$3.80 \quad 2.21$

$\begin{array}{ll}1.41 & 0.78\end{array}$

Number of stock days

339,720

365,469

340,094

333,757

348,907

The sample of stocks is restricted to NYSE common stocks trading at least 100 days in the year and never trading below $\$ 3.00$.

** The times are based on the trade times indicated on the Fitch data tapes and the following NYSE hours: 10:00 a.m. to 4:00 p.m. (EST) from September 1, 1982 through September 27, 1985; and 9:30 a.m. to 4:00 p.m. from September 30, 1985 to December 31, 1986. 
the stocks in the lowest daily dollar volume decile, on average, did not trade until over one hour after the exchange had opened. For less active stocks, the opening transaction is less likely to represent an auction, because relatively few orders accumulated overnight; instead, the opening transaction is likely to represent the execution of an order submitted after the exchange opening. As dollar volume increases, the average time until the first transaction declines to a low of 4.15 minutes in decile nine. Thus, the opening transaction in higher-volume stocks is likely to reflect an opening auction of orders that have accumulated overnight. The announcement of the opening price may take time because the specialist opens in sequence the stocks for which he is responsible. Furthermore, the opening of certain stocks can be delayed when large imbalances have accumulated overnight. In a delayed opening, the specialist follows disclosure procedures for attracting offsetting orders and is monitored by a floor governor. The increase in the average time to opening for the largest volume decile (to 4.98 minutes in 1986) reflects delayed openings.

The average time between the last trade and the close of the market decreases monotonically with volume to less than a minute for the highest volume stocks.

The data in Table 1 may be used to infer the extent to which trading in a stock index portfolio, such as the S\&P 500, lags the stock market open and ends before the stock market close. Because S\&P 500 stocks are generally high dollar-volume stocks, most of the S\&P 500 stocks are likely to be in the largest four deciles. The average time to open does not vary much across these deciles; for example, it varies between 4.15 and 5.46 minutes in 1986. There is considerably more variation across the largest four deciles at the close, between 0.78 and 6.39 minutes in 1986 .

\section{Volume at the Opening}

Opening-share volume is defined as the number of shares traded in the first transaction. When more than one transaction is reported at the opening price, the volume of trading at the same price in the minute after the first transaction is aggregated. Both opening-share volume and total-share volume are computed for each stock on each day. Table 2 summarizes the average proportions of total daily volume accounted for by the opening trades during the years 1982 through 1986. 


\section{TABLE 2}

\section{Volume at the Opening as a \\ Proportion of Daily Volume*}

$\begin{array}{lllll}1982 & 1983 & 1984 & 1985 & 1986\end{array}$

Average daily dollar volume

$$
(\times 1,000)
$$

2,012

2,007

2,604

3,725

Average proportion of volume at open **

$\begin{array}{llllll}\text { All stock days } \quad 0.1537 & 0.1381 & 0.1396 & 0.1268 & 0.1059\end{array}$

By daily dollar volume decile

$\begin{array}{cccccc}\text { Smallest } & 0.4544 & 0.3691 & 0.4006 & 0.3688 & 0.3276 \\ 2 & 0.2209 & 0.1849 & 0.1962 & 0.1769 & 0.1498 \\ 3 & 0.1679 & 0.1478 & 0.1543 & 0.1392 & 0.1152 \\ 4 & 0.1389 & 0.1292 & 0.1308 & 0.1182 & 0.0946 \\ 5 & 0.1221 & 0.1159 & 0.1143 & 0.1025 & 0.0804 \\ 6 & 0.1082 & 0.1041 & 0.0997 & 0.0897 & 0.0670 \\ 7 & 0.0946 & 0.0944 & 0.0876 & 0.0794 & 0.0621 \\ 8 & 0.0851 & 0.0846 & 0.0773 & 0.0705 & 0.0557 \\ 9 & 0.0734 & 0.0776 & 0.0697 & 0.0635 & 0.0527 \\ \text { Largest } & 0.0720 & 0.0736 & 0.0654 & 0.0593 & 0.0533\end{array}$

$\begin{array}{llllll}\text { Number of stock days } \quad 339,720 & 365,469 & 340,094 & 333,757 & 348,907\end{array}$

The sample of stocks is restricted to NYSE common stocks trading at least 100 days in the year and never trading below $\$ 3.00$.

** Opening dollar volume is defined as the value of all trades at the first price occurring at the same time.

In the period 1982 through 1986 , daily dollar volume nearly tripled, and opening volume as a fraction of daily volume fell from an average of 15.37 percent to an average of 10.59 percent. Variation in the proportion of the daily volume that occurs at the open across dollar-volume deciles is large. A larger proportion of daily trading volume appears to take place at the open for less active stocks. In 1986, for example, the proportion is about 32.8 percent for the smallest daily volume decile and 5.3 percent for the largest dollar-volume decile. 
Although opening volume is a smaller proportion of total daily volume in high-volume stocks than in low-volume stocks, the rate of trading over the interval up to the opening trade is greater for high-volume stocks. With 390 minutes in the trading day, the 1986 opening volume in the largest-volume decile amounts to $20.79(0.0533 \times 390)$ minutes of trading. ${ }^{1}$ Because the time to open averages 4.98 minutes for the largest stocks (Table 1), opening volume is 4.17 times normal volume. In the case of the lowest-volume stocks, opening volume accounts for about $127.76(0.3276 \times 390)$ minutes of trading. Because the time to open takes about 67.40 minutes, opening volume is 1.9 times normal volume in the lowest-volume stocks. In other words, relative to the average rate of trading during the day, opening volume is at a greater rate for large stocks than for small stocks, which indicates that small stocks are less likely to accumulate orders overnight.

\section{Day-of-the-Week Effects}

The timing of the first and last trade and volume at the opening are examined for day-of-the-week variation. For each day, the average minutes to opening, average minutes to close, average dollar volume at the opening, and average proportion of daily volume at the opening are calculated across all stocks traded on that day. Day-of-the-week effects are estimated in a regression equation of the following form:

$$
y=a_{0}+a_{1} T u+a_{2} W e+a_{3} T h+a_{4} F r+e,
$$

where $y$ is the variable of interest, such as minutes to open, and $T u, W e, T h$, and $\mathrm{Fr}$ are dummy variables for Tuesday through Friday, respectively. The intercept term $a_{0}$ picks up the Monday effect, so when the estimated coefficients of $a_{1}$ through $a_{4}$ are added to $a_{0}$, the mean values by day of the week are created. Table 3 contains these results. Beneath each mean in parentheses is a $t$-statistic. The $t$-statistic for Monday tests the null hypothesis that the Monday return equals zero. The $t$-statistic beneath each of the remaining days corresponds to the null hypothesis that the mean for that day is significantly different from Monday.

\footnotetext{
${ }^{1}$ Beginning on September 30, 1985, the NYSE opened 30 minutes earlier. Prior to that time, the exchange hours were 10:00 a.m. to 4:00 p.m. (EST).
} 


\section{TABLE 3}

\section{Time Statistics by Day of the Week}

\begin{tabular}{|c|c|c|c|c|c|}
\hline \multicolumn{6}{|l|}{ Averages } \\
\hline Minutes to open & $\underbrace{16.218}$ & $\begin{array}{r}16.361 \\
(0.38)\end{array}$ & $\begin{array}{l}17.012 \\
(2.13)\end{array}$ & $\begin{array}{l}17.508 \\
(3.44)\end{array}$ & $\begin{array}{l}18.015 \\
(4.78)\end{array}$ \\
\hline Minutes to close & $\begin{array}{r}24.038 \\
(59.23)\end{array}$ & $\begin{array}{c}24.160 \\
(0.22)\end{array}$ & $\begin{array}{c}24.301 \\
(0.47)\end{array}$ & $\begin{array}{c}24.576 \\
(0.95)\end{array}$ & $\begin{array}{c}24.484 \\
(0.79)\end{array}$ \\
\hline $\begin{array}{l}\text { Dollar volume } \\
\text { at open } \\
\text { (in thousands) }\end{array}$ & $\begin{array}{l}135,339 \\
(27.30)\end{array}$ & 159,935 & 165,858 & $\begin{array}{r}167,189 \\
(4.59)\end{array}$ & $\begin{array}{r}166,091 \\
(4.43)\end{array}$ \\
\hline $\begin{array}{l}\text { Proportion of daily } \\
\text { volume at open }\end{array}$ & $\begin{array}{r}0.131 \\
(84.98)\end{array}$ & $\begin{array}{c}0.131 \\
(0.19)\end{array}$ & $\begin{array}{c}0.132 \\
(0.35)\end{array}$ & $\begin{array}{c}0.134 \\
(1.50)\end{array}$ & $\begin{array}{c}0.138 \\
(3.19)\end{array}$ \\
\hline Number of days & 241 & 259 & 257 & 252 & 251 \\
\hline \multicolumn{6}{|c|}{$\begin{array}{l}\text { The sample of stocks is restricted to NYSE common stocks trading at least } 100 \text { days in the year and } \\
\text { never trading below } \$ 3.00 \text {. } \\
\text { Opening dollar volume is defined as the value of all trades at the first price occurring at the same } \\
\text { time. } \\
\text { Parentheses indicate } t \text {-statistics. }\end{array}$} \\
\hline
\end{tabular}

The average number of minutes until the first transaction is lowest on Monday, 16.2 minutes, and highest on Friday, 18 minutes. The average time to opening on Friday exceeds that of Monday by 1.80 minutes, which is a statistically significant difference. The average time between the last transaction and the close of the market is also lowest on Monday, 24.04 minutes, but the difference between Monday and the other days is not statistically significant.

Opening volume is lowest on Monday, averaging $\$ 135,339$ over all stocks and all Mondays. Dollar opening volume is significantly higher on days other than Monday. The proportion of volume at the opening, about 13 percent, is virtually identical for all days. Institutional volume may be lowest on Monday 
because many institutional money managers may take a day to formulate trading decisions after the weekend layoff. ${ }^{2}$

We looked at the timing of trading and opening volume by year, by volume decile, and by day of the week. These results confirm the findings reported in this section. ${ }^{3}$

${ }^{2}$ Lakonishok and Maberly (1990) argue that the average negative return on Monday can be explained by the fact that individual investors trade more on Monday than other days of the week and tend to be heavier net sellers on Monday than other days.

${ }^{3}$ Data by year, by volume decile, and by day of the week are available from the authors. 


\section{Return Volatility}

We now present the results for tests of return volatility, serial dependence in returns, daytime versus overnight volatility, and day-of-the-week effects on returns and volatility.

\section{Return Volatility at the Opening}

The analysis of return volatility begins with the computation of return variances, which are calculated for each stock in each month during the period 1982 to 1986. The ratio of the return variances for each stock in each month is computed, and then the ratios are averaged across stocks in each month and across the 60 months of the sample period. The sample is positioned into quintiles according to daily dollar volume. The results are reported in Table 4.

The average open-to-open/close-to-close variance ratio of 1.1329 indicates that on average the open-to-open variance is about 13 percent higher than the close-to-close variance. The average variance ratio is also calculated for the stocks within each daily dollar-volume quintile. The average ratio for the stocks in the most active quintile is 1.1734 . This compares with the value of 1.2 reported by Amihud and Mendelson (1987) in their study of 30 Dow Jones Industrial Average (DJLA) stocks.

The second row of Table 4 reports the standard errors of the variance ratios. These standard errors indicate that the variance ratio is significantly different from one. Under the null hypothesis, the probability of observing the ratio 1.1329 (all stocks) is less than 0.1 percent. Furthermore, the volatility ratio for high-volume stocks significantly exceeds the volatility ratio for lowvolume stocks. Because high-volume stocks are more likely to be opened by an auction procedure, these results suggest that the opening auction procedure is associated with increased volatility. Because the average variance ratio 


\section{TABLE 4}

\section{Statistics on Open-to-Open Returns Relative to Close-to-Close Returns*}

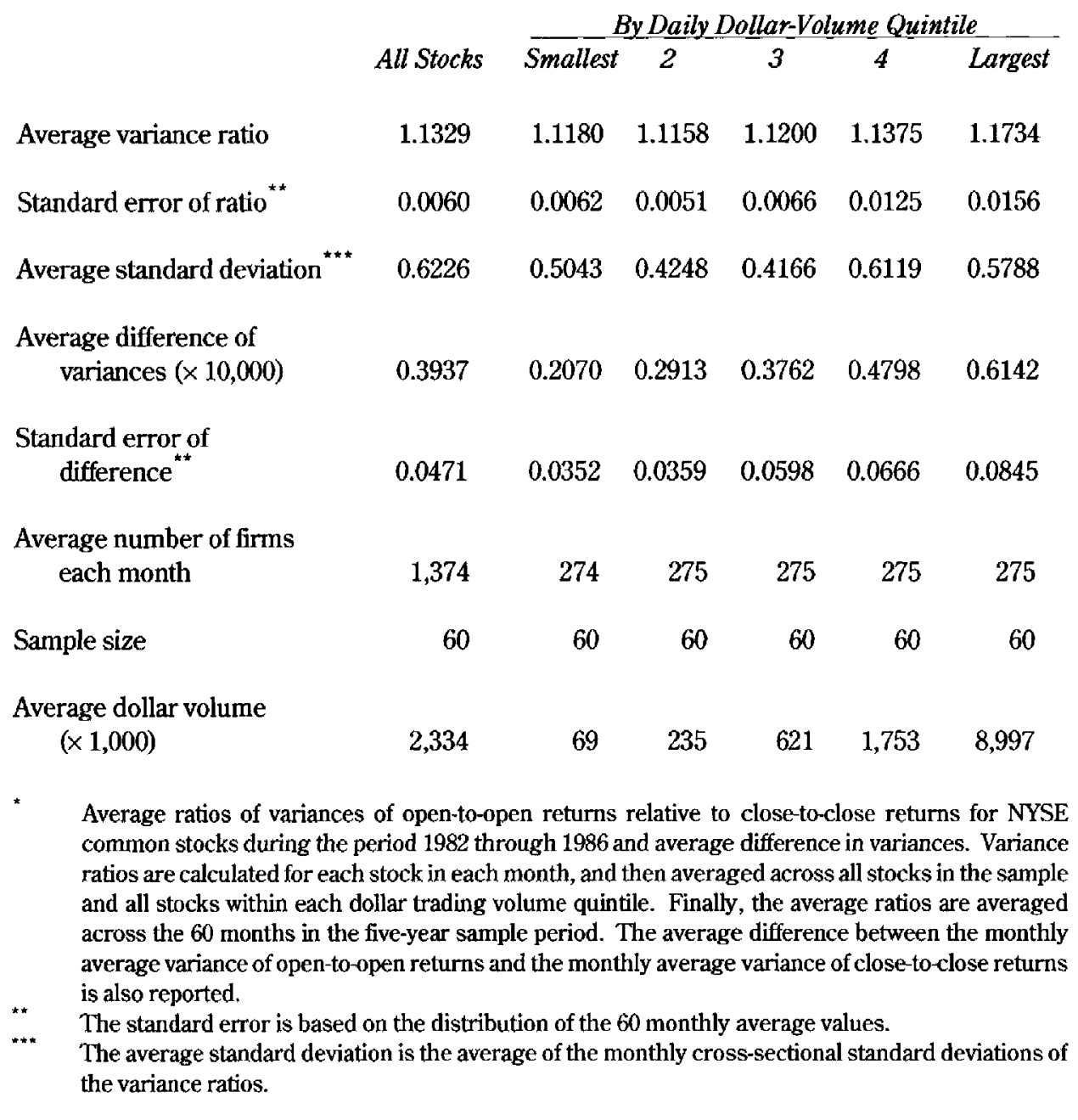


is biased upward by virtue of Jensen's inequality, we also report the average difference in variances in the fourth row of Table $4 .^{1}$ The null hypothesis that the open-to-open return variance equals the close-to-close return variance is rejected.

\section{Serial Dependence in Returns}

The variance ratio results indicate that structural price volatility at the open is greater than at the close. The greater volatility of open-to-open returns indicates that trading shocks have a greater influence at the open than at the close. In this section, we examine the first-order serial correlations in returns surrounding the open.

\section{Reversals}

The greater volatility of open-to-open returns over close-to-close returns implies that the correlation between the daytime and the following overnight return, $\rho\left(r_{d, t-1}, r_{n, t}\right)$, exceeds the correlation between the overnight and the following daytime return, $\rho\left(r_{n, t}, r_{d, t}\right){ }^{2}$ The average serial correlations reported in the first two panels of Table 5 confirm this. The results in the table show that $\rho\left(r_{d, t-1}, r_{n, t}\right)$ is greater than $\rho\left(r_{n, t}, r_{d, t}\right)$ for all stocks and in each volume category.

The last two panels of Table 5 show that the serial correlation in open-toopen returns, $\rho\left(r_{o, t-1}, r_{o, t}\right)$, is negative in all volume categories, whereas the serial correlation in close-to-close returns, $\rho\left(r_{c, t-1}, r_{c, t}\right)$, is negative in only the two smallest-volume quintiles and is positive in the other volume quintiles. This result means that open-to-open returns are more likely to be reversed than close-to-close returns. Indeed, in close-to-close returns, there is evidence of price continuations among high-volume stocks. Price reversals are typical in dealer markets as a result of price movements between the bid and the ask (see Roll 1984 and Stoll 1989). Contrary to the null hypothesis, openings accentuate price reversals relative to those observed in closing prices.

The serial correlation in open-to-open returns depends in part on the serial correlation between the overnight return and the return the following day,

\footnotetext{
${ }^{1}$ The extent of the bias is reflected in the ratios of average variances corresponding to the average variance ratios reported in the first row of Table 4 . These are 1.0834, 1.0426, 1.0596, $1.0761,1.1041$, and 1.1428 .

${ }^{2}$ Serial correlations rather than serial covariances are reported to standardize across stocks.
} 


\section{TABLE 5}

\section{Average Serial Correlations of Returns in Adjacent Periods*}

\begin{tabular}{|c|c|c|c|c|c|c|}
\hline & \multirow[b]{2}{*}{ All Stocks } & \multicolumn{5}{|c|}{ By Daily Dollar-Volume Quintile } \\
\hline & & Smallest & 2 & 3 & 4 & Largest \\
\hline \multicolumn{7}{|l|}{$\rho\left(r_{n, t}, r_{d, t}\right)$} \\
\hline Average & -0.0531 & -0.1224 & -0.0672 & -0.0396 & -0.0266 & -0.0098 \\
\hline Standard error $^{* *}$ & 0.0033 & 0.0035 & 0.0043 & 0.0040 & 0.0040 & 0.0063 \\
\hline Average standard deviation ${ }^{* * *}$ & 0.2566 & 0.2662 & 0.2610 & 0.2542 & 0.2467 & 0.2339 \\
\hline \multicolumn{7}{|l|}{$\rho\left(r_{d, t-1,}, r_{n, t}\right)$} \\
\hline Average & 0.0202 & -0.0947 & -0.0144 & 0.0298 & 0.0574 & 0.1225 \\
\hline Standard error ${ }^{\star \star}$ & 0.0064 & 0.0047 & 0.0059 & 0.0068 & 0.0072 & 0.0105 \\
\hline Average standard deviation ${ }^{\star \star *}$ & 0.2725 & 0.2628 & 0.2637 & 0.2624 & 0.2626 & 0.2557 \\
\hline \multicolumn{7}{|l|}{$\rho\left(r_{o, t-1}, r_{o, t}\right)$} \\
\hline Average & -0.0480 & -0.1130 & -0.0510 & -0.0271 & -0.0229 & -0.0263 \\
\hline Standard error ${ }^{\star *}$ & 0.0033 & 0.0035 & 0.0041 & 0.0035 & 0.0038 & 0.0068 \\
\hline Average standard deviation ${ }^{\star \star \star}$ & 0.2312 & 0.2478 & 0.2356 & 0.2300 & 0.2174 & 0.2053 \\
\hline \multicolumn{7}{|l|}{$\rho\left(r_{c, t-1}, r_{c, t}\right)$} \\
\hline Average & -0.0138 & -0.0936 & -0.0268 & 0.0021 & 0.0159 & 0.0334 \\
\hline Standard error ${ }^{\star \star}$ & 0.0039 & 0.0044 & 0.0043 & 0.0042 & 0.0043 & 0.0055 \\
\hline Average standard deviation ${ }^{\star \star \star}$ & 0.2336 & 0.2470 & 0.2368 & 0.2280 & 0.2204 & 0.2095 \\
\hline \multicolumn{7}{|l|}{ Average number of firms } \\
\hline per month & 1,374 & 274 & 275 & 275 & 275 & 275 \\
\hline Sample size & 60 & 60 & 60 & 60 & 60 & 60 \\
\hline \multicolumn{7}{|l|}{ Average dollar volume } \\
\hline$(\times 1,000)$ & 2,334 & 69 & 235 & 621 & 1,753 & 8,997 \\
\hline
\end{tabular}

* Average serial correlations of returns in adjacent periods for NYSE common stocks during the period 1982 through 1986. Serial correlations are calculated for each stock in each month, and are then averaged across all stocks in the sample and all stocks within each dollar trading volume quintile. Finally, the average serial correlations are averaged across the 60 months in the five-year sample period.

*** The standard error is based on the distribution of the 60 monthly average serial correlation estimates.

*** The average standard deviation is the average of the monthly cross-sectional standard deviations of the serial correlations. 
$\rho\left(r_{n, t}, r_{d, t}\right){ }^{3}$ That correlation averages -0.0531 and is significantly different from zero. The negative correlation is much more pronounced for low-volume stocks than for high-volume stocks, however. The correlation in close-to-close returns depends in part on the serial correlation between the daytime return and the following night return, $\rho\left(r_{d, t-1}, r_{n, t}\right) .{ }^{4}$ That correlation averages 0.0202 over all stocks. It is negative for the two lowest-volume categories and positive for the three highest-volume categories.

The serial correlation results for the components of the 24-hour return indicate that the overnight return tends to be reversed by the following daytime return. This is an indication of a temporary price deviation at the opening. On the other hand, the daytime return is much less likely to be reversed by the return of the following night. This suggests that the closing price is less likely to reflect a temporary deviation. Indeed, the positive serial dependence between the daytime return and the following overnight return observed in the high-volume stocks is evidence of a price continuation.

Price continuations after the close and price reversals after the opening are consistent with a market in which public buying or selling pressure carries over from the close to the following opening. Providers of immediacy, such as the specialists, are compensated by price reversals during the trading day following the opening. Additional insight into these issues is provided later in this study when we analyze the effect of the volume of trading on volatility and reversals.

\section{Implied Bid-Ask Spreads}

Price reversals reflect the compensation to suppliers of immediacy for taking the other side of transactions initiated by active traders. In a dealer market, reversals reflect movements between bid and ask prices. In an auction market, similar reversals are observed even though no bid-ask spread is quoted because suppliers of immediacy back away from active traders. Under the

${ }^{3}$ Because $r_{o, t} \equiv r_{d, t-1}+r_{n, t}$, the first-order serial covariance in open-to-open returns may be written as $\operatorname{cov}\left(r_{d, t-2}, r_{d, t-1}\right)+\operatorname{cov}\left(r_{d, t-2}, r_{n, t}\right)+\operatorname{cov}\left(r_{n, t-1}, r_{d, t-1}\right)+\operatorname{cov}\left(r_{n, t-1}, r_{n}, t\right)$. The only term in the summation involving returns in adjacent time periods is the serial covariance between the

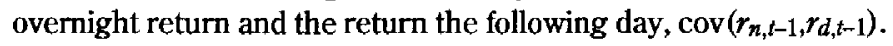

${ }^{4}$ Because $r_{c, t} \equiv r_{n, t}+r_{d, t}$, the serial covariance in close-to-close returns may be written as $\operatorname{cov}\left(r_{n, t-1}, r_{n, t}\right)+\operatorname{cov}\left(r_{n, t-1}, r_{d, t}\right)+\operatorname{cov}\left(r_{d, t-1}, r_{n, t}\right)+\operatorname{cov}\left(r_{d, t-1}, r_{d, t}\right)$. The only term in the summation involving returns in adjacent time periods is the serial covariance between the daytime return and the return the following night, $\operatorname{cov}\left(r_{d, t-1}, r_{n, t}\right)$. 
assumption of market efficiency and certain other assumptions about dealer behavior, Roll (1984) shows that the bid-ask spread is given by $S=2 \sqrt{-\operatorname{cov}}$, where cov is the first-order serial covariance of returns. Although Stoll (1989) and others show that Roll's procedure underestimates the quoted bid-ask spread, the procedure conveys the relative magnitude of transaction costs.

We used Roll's procedure to calculate the bid-ask spreads implied by the serial covariances of returns between the overnight return and the return the following day, between the daytime return and the return the following night, between successive open-to-open returns, and between successive close-toclose returns. Serial covariances are calculated for each stock in each month and then averaged across stocks in each dollar-volume quintile in each month. The average serial covariances for each quintile in each month are used to compute the implied spreads, and the monthly spreads are averaged across the 60 months of the sample to generate the results reported in Table 6 .

The different return series yield startlingly different implied spreads. The implied spread based on closing prices-the data used by Roll-is small ( 0.0971 percent) when averaged over all stocks in the period 1982 to 1986 , and it is negative for the most active quintile of stocks $(-0.5505)$. A negative spread is unreasonable and simply reflects the fact that the underlying serial covariance is estimated to be positive. Roll also found a small average spread of 0.298 percent in the period 1963 to 1982 and a larger number of stocks with negative implied spreads. A positive serial dependence is also present between the daytime return and the following overnight return. The spread implied by this series of returns is negative for every trading-volume category except the lowest. The evidence implies that the momentum of prices during the day is carried over to the next morning's open.

On the other hand, the implied spread based on open-to-open returns yields a significant positive spread for all volume categories. Over all stocks, the spread implied by open-to-open returns is 0.8983 percent, or $\$ 0.49$ on a $\$ 55.00$ stock. This number is statistically and economically significant. ${ }^{5}$ It is particularly significant economically when it is considered that the Roll procedure underestimates the quoted spread. A significant positive spread is also

\footnotetext{
${ }^{5}$ McInish and Wood (1989) find that the quoted spread is higher in the first 15 minutes of the trading day than later in the trading day, although the difference is not as great as that between the implied spreads based on open-to-open returns and close-to-close returns.
} 


\section{TABLE 6}

\section{Average Implied Bid-Ask Spreads for All Stocks and for Stocks Classified by Daily Dollar-Volume Quintile in All Months during the Period 1982 through 1986*}

\begin{tabular}{|c|c|c|c|c|c|c|}
\hline \multirow{3}{*}{\multicolumn{2}{|c|}{$\begin{array}{l}\text { Dollar-Volun } \\
\text { Quintile }\end{array}$}} & & \multicolumn{4}{|c|}{ Implied Bid-Ask Spreads (In Percent) } \\
\hline & & & & & & \\
\hline & & & $\left(r_{n, t}, r_{d, t}\right)$ & $\left(r_{d, t-1,}, r_{n, t}\right)$ & $\left(r_{o, t}, r_{o, t-1}\right)$ & $\left(r_{c, t,}, r_{c, t-1}\right)$ \\
\hline \multirow{3}{*}{\multicolumn{2}{|c|}{ Smallest }} & Average spread & 1.0626 & 0.7942 & 1.3327 & 1.0339 \\
\hline & & Standard error ${ }^{\star \star}$ & 0.0176 & 0.0477 & 0.0323 & 0.0641 \\
\hline & & Proportion positive & 0.6825 & 0.6423 & 0.6752 & 0.6436 \\
\hline \multirow{3}{*}{\multicolumn{2}{|c|}{2}} & Average spread & 0.7044 & -0.0292 & 0.8217 & 0.2624 \\
\hline & & Standard error ${ }^{* \star}$ & 0.0313 & 0.0801 & 0.0719 & 0.0968 \\
\hline & & Proportion positive ${ }^{* *}$ & 0.6073 & 0.5200 & 0.5855 & 0.5381 \\
\hline \multirow{3}{*}{\multicolumn{2}{|c|}{3}} & Average spread & 0.4375 & -0.4997 & 0.5836 & -0.1812 \\
\hline & & Standard error ${ }^{\star *}$ & 0.0465 & 0.0770 & 0.0774 & 0.0969 \\
\hline & & Proportion positive & 0.5600 & 0.4545 & 0.5418 & 0.4873 \\
\hline \multirow{3}{*}{\multicolumn{2}{|c|}{4}} & Average spread & 0.2290 & -0.6996 & 0.4895 & -0.3858 \\
\hline & & Standard error ${ }^{* \star}$ & 0.0631 & 0.0636 & 0.0939 & 0.0935 \\
\hline & & Proportion positive ${ }^{* \star *}$ & 0.5418 & 0.4073 & 0.5345 & 0.4582 \\
\hline \multirow{3}{*}{\multicolumn{2}{|c|}{ Largest }} & Average spread & 0.2102 & -0.9066 & 0.6006 & -0.5505 \\
\hline & & Standard error ${ }^{* *}$ & 0.0653 & 0.0593 & 0.1176 & 0.0884 \\
\hline & & Proportion positive & 0.5200 & 0.3164 & 0.5455 & 0.4291 \\
\hline \multirow{3}{*}{\multicolumn{2}{|c|}{ All stocks }} & Average spread & 0.6602 & -0.2943 & 0.8983 & 0.0971 \\
\hline & & Standard error ${ }^{\star \star}$ & 0.0245 & 0.0784 & 0.0536 & 0.0884 \\
\hline & & Proportion positive & 0.5822 & 0.4680 & 0.5764 & 0.5131 \\
\hline \multicolumn{7}{|c|}{$\begin{array}{l}\text { Spreads are calculated according to Roll's }(1984) \text { model as } 2 \sqrt{-\operatorname{cov}} \text {. For the sequence of returns } \\
\text { listed at the top of each column, the serial covariances for stocks in each month are averaged across } \\
\text { all stocks in each month in each volume category. The implied spread is calculated from the average } \\
\text { serial covariance in that month and average values over the } 60 \text { months in the data set are reported } \\
\text { in the table. If the average serial covariance is positive, we take the square root of the absolute value } \\
\text { of the covariance and reattach the negative sign. } \\
\text { The standard error is based on the distribution of the } 60 \text { monthly average implied spread estimates. } \\
\text { The positive proportion is the average number of stocks with positive spreads divided by average } \\
\text { number of stocks in the volume category. Each volume category contains an average of } 275 \text { stocks, } \\
\text { except the smallest, which contains } 274 \text {. }\end{array}$} \\
\hline
\end{tabular}


implied by the serial covariance between the overnight return and the return the following day. Over all stocks, the spread is 0.6602 percent $(\$ 0.36)$. Furthermore, it is positive for all volume categories and declines from the smallest-volume category (1.0626 percent, $\$ 0.58)$ to the largest-volume category $(0.2102$ percent, $\$ 0.12)$. These results imply that prices established at the open tend to be reversed during the rest of the day, and they are consistent with the view that the volatility of open-to-open returns is due in part to temporary price deviations necessary to compensate providers of liquidity at the open. To the extent the specialist is an important provider of liquidity at the open, he benefits from the price reversals.

\section{Daytime Versus Overnight Volatility}

Empirical research on daytime versus overnight volatility indicates that the variance of daytime returns is greater than the variance of nighttime returns, even though the number of daytime hours is less than the number of nighttime hours. Oldfield and Rogalski (1980) report that the variance of daytime (open to close) returns is 4.26 times higher than the variance of overnight (previous close to open) returns for a sample of five firms during the 39-month period October 1, 1974, through December 31, 1977. Because trading occurs over 6 hours and nontrading occurs over 18 hours, the per-hour ratio of variances implied by this number is 12.78 . French and Roll (1986) use daily closing prices of NYSE and American Stock Exchange (AMEX) stocks during the 20-year period 1963 through 1982, and they consider the fact that exchanges are closed weekends and holidays to infer that the per-hour ratio of variances in trading versus nontrading periods is 13.2. French and Roll further infer from their results that the higher volatility during trading hours is due in large part to the greater arrival of private information that is revealed in trading, rather than to the greater arrival of public information.

We analyzed the trading/nontrading volatility effect. Table 7 contains the average variance ratios of daytime returns to overnight returns for NYSE stocks during the sample period January 1982 through December 1986. The average of the monthly ratios is approximately 5.4 , which indicates an average per-hour ratio of daytime to overnight variances of 16.2. This number is higher than the values reported in the other two studies and may reflect, in part, the greater trading activity in recent years. The greater daytime volatility may be a result of the arrival of more public information during the day, the arrival of 
private information revealed only through trading, or the noise induced by liquidity traders and the cost of supplying immediacy.

A strong positive association between the average variance ratio and the daily dollar-volume quintile is evident in Table 7. High-volume stocks have greater daytime volatility relative to nighttime volatility. Several factors may explain this finding. First, because noise and private information are related to volume, it may be that the greater daytime volatility is due in part to private information and to noise induced by liquidity traders rather than to public information. Second, because the overnight return variance is heavily influenced by the variance of the opening price, the volume pattern in Table 7 implies that opening procedures have a greater impact on the volatility of low-volume stocks than high-volume stocks. Third, technical factors also influence the relation between the variance ratio and trading volume: because low-volume stocks are slow to open, their opening prices (and thus their overnight volatility) tend to reflect the market-wide volatility already incorporated in the daytime returns of more active stocks.

It is striking that the average return during the night-a period of 18 hours a day during the week and 66 hours over the weekend-is small compared to the daytime return that spans only 6 hours: the average nighttime return is typically less than one-third the average daytime return. Both risk and return appear to accrue at higher rates during the day. Daytime risk and return are significantly greater than nighttime risk and return.

\section{Day-of-the-Week Effects on Returns and Volatility}

In this section we analyze how average returns, volatility, and implied bid-ask spreads vary by the day of the week. Puzzling patterns in day-of-the-week returns-in particular the negative return over the weekend-have been reported in numerous studies. ${ }^{6}$

${ }^{6}$ Empirical evidence is provided in French (1980), Gibbons and Hess (1981), Keim and Stambaugh (1984), Rogalski (1984), Harris (1986), and Lakonishok and Maberly (1990). Theoretical models describing interday return patterns are contained in Admati and Pfleiderer (1988) and Foster and Viswanathan (1990). 


\section{TABLE 7}

\section{Average Ratios of Variances of Open-to-Close Returns $\left(r_{d, t}\right)$ Relative to Close-to-Open Returns $\left(r_{n, t}\right)^{\star}$}

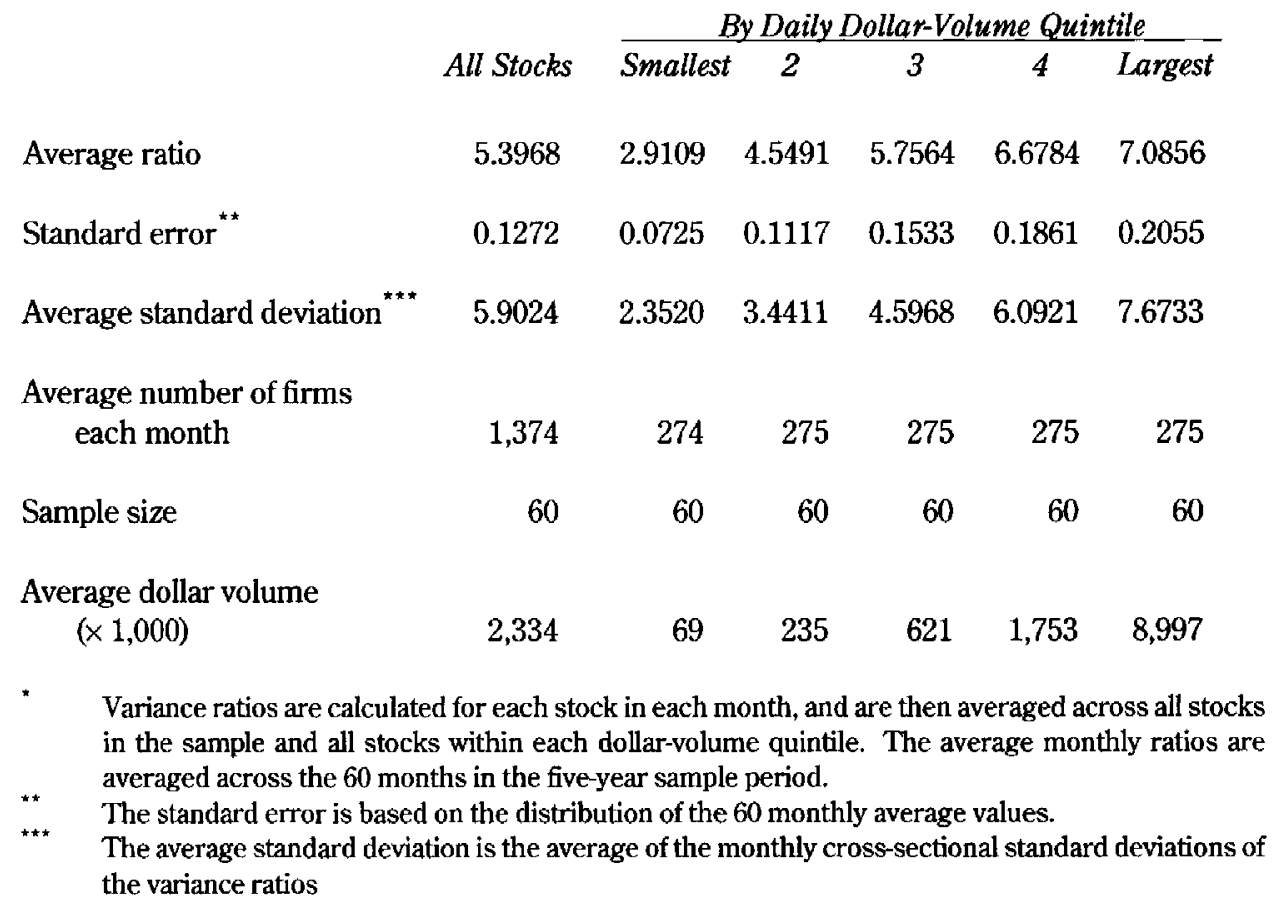

\section{Patterns in Returns}

Early studies of day-of-the-week effects in returns analyzed stock index returns or daily returns for individual stocks, but not individual stock returns within the day. More recently, Harris (1986) examined individual stock returns at 15-minute intervals for all NYSE stocks over 296 trading days from December 1,1981 , to January 31,1983 . Our focus is less detailed in that we examine daytime, nighttime, close-to-close, and open-to-open returns of individual stocks; however, we consider a longer time period, 1,182 trading days in the years 1982 through 1986. 
Our empirical procedure is as follows. For each day, the average return is calculated across all stocks traded on that day. ${ }^{7}$ The 1,182 average daily return observations are then used as the dependent variable $y$ in the regression,

$$
y=a_{0}+a_{1} T u+a_{2} W e+a_{3} T h+a_{4} F r+e,
$$

where $T u, W e, T h$, and $F r$ are dummy variables for Tuesday through Friday, respectively. The intercept term $a_{0}$ picks up the Monday effect, so when the estimated coefficients of $a_{1}$ through $a_{4}$ are added to $a_{0}$, the mean values by day of the week are created. Table 8 contains the results of these regressions. The $t$-statistic beneath each of the remaining days corresponds to the null hypothesis that the mean return for that day is significantly different from Monday. Separate regressions are estimated for each of four types of returns: the daytime return, $r_{d, i} ;$ the nighttime return, $r_{n, i} ;$ the open-to-open return, $r_{o, i} ;$ and the close-to-close return, $r_{c, t}$.

Like other investigators, we find a negative weekend return and positive returns during the rest of the week. The mean average return from the close of Friday to the close of Monday is -0.1054 percent and is significantly different from zero. Of this amount, -0.0439 percent accrues from Friday close to Monday open (nighttime return), and -0.0615 percent accrues during the day on Monday. Our estimates are smaller than those of Harris (1986), who finds a weekend return of -0.202 , a nighttime return of -0.095 , and a daytime return of -0.105 , but this is due in part to the downward bias in the average of geometric returns. The return from Thursday close to Friday close, 0.1609 percent, is the largest return in the week. It comprises a nighttime return of 0.0418 percent and a daytime return of 0.1192 percent. These returns are also slightly smaller than those in Harris (1986). In our sample, daytime returns

\footnotetext{
${ }^{7}$ The daily average return we calculate is not the return of a portfolio, because we define return as the $\log$ of the price ratio. A portfolio return would be the $\log$ of the average price ratio, whereas we calculate the average of the $\log$ price ratios. The average of the log price ratios is biased downward with respect to the actual portfolio return. We are interested in the return of the typical stock across days of the week, not the portfolio return over time. We average across stocks each day because stock returns are cross-sectionally correlated and we cannot treat each stock as an independent observation. Stock returns tend to be uncorrelated over time, so we can treat the sample of 1,182 days as independent.
} 


\section{TABLE 8}

\section{Mean Average Percentage Returns and $t$-statistics by Day of the Week}

$\begin{array}{lrrrrr} & \text { Monday } & \text { Tuesday } & \text { Wednesday } & \text { Thursday } & \text { Friday } \\ \text { Daytime percentage return } & -0.0615 & 0.0314 & 0.0776 & 0.0894 & 0.1192 \\ & (-1.590) & (1.729) & (2.583) & (2.789) & (3.337) \\ \text { Nighttime percentage return } & -0.0439 & 0.0166 & 0.0114 & 0.0231 & 0.0418 \\ & (-2.522) & (2.501) & (2.283) & (2.754) & (3.517) \\ \text { Open-to-open percentage return } & 0.0695 & -0.0420 & 0.0451 & 0.0921 & 0.1341 \\ & (1.382) & (-1.595) & (-0.349) & (0.322) & (0.918) \\ \text { Close-to-close percentage return } & -0.1054 & 0.0481 & 0.0890 & 0.1125 & 0.1609 \\ & (-2.333) & (2.445) & (3.091) & (3.448) & (4.210) \\ \text { Number of days } & & & & & \\ & 241 & 259 & 257 & 252 & 251\end{array}$

Day-of-the-week effects are estimated in a regression equation of the following form:

$$
y=a_{0}+a_{1} T u+a_{2} W e+a_{3} T h+a_{4} F r+e,
$$

where $y$ is the variable of interest, such as daytime return, and $T u$, We, Th, and $F r$ each take on the value one if the observation is for the indicated day and zero otherwise. The unit of observation is the average value across all stocks on a given day. The value in the table for Monday is âo, and the $t$-statistic for Monday tests the null hypothesis that the Monday mean is zero. The value in the table for the other days is the intercept plus the estimated coefficient for that day, and the $t$ values for the remaining days test the null that the difference from Monday is zero. Parentheses indicate $t$-statistics.

increase during the week. Nighttime returns also increase during the week, but they are very small.

Changes in the public's buying and selling pressure may explain the day-of-the-week effects on returns. Lakonishok and Maberly (1990) suggest that individual investors tend to sell on Mondays. The observed day-of-theweek returns may reflect the price changes necessary to induce the specialist and other market makers to take the other side of public transactions. If so, one would expect specialists to be buying at the beginning of the week and 
selling at the end of the week. That hypothesis is testable, but it is beyond the scope of this study.

\section{Patterns in Variances}

In earlier sections of this study, variance ratios calculated from different returns spanning slightly different time intervals have been examined. The results show that open-to-open returns are more variable than close-to-close returns, and that daytime returns are significantly more volatile than nighttime returns. We now investigate how the variance of returns changes across days of the week to determine whether the greater variability of open-to-open returns and nighttime returns occurs equally on all days of the week.

Return variances are calculated by day of the week using all the data for each stock that has at least 100 days of data. The results in Table 9 are as expected. $^{8}$ Daytime variances are much larger than nighttime variances on each day of the week; that is, the variance of open-to-open returns exceeds the variance of close-to-close returns.

Differences across days of the week are evident only in the nighttime variance. The Monday nighttime variance calculated from the Friday close to the Monday open exceeds the nighttime variance on the other days of the week, as one might expect. Surprisingly, however, the Monday nighttime variance is only 28 percent greater than the nighttime variance of the other four days, even though the time elapsed is 267 percent greater. Furthermore, the Monday nighttime variance is significantly less than any daytime variance that spans only six hours. For example, the weekend variance is 62 percent less than the Monday daytime variance. Possibly, public information disclosed over a weekend takes time to be incorporated into prices; this would lead one to expect a greater daytime variance on Monday than on other days. In fact, the daytime variance on Monday is not greater than on other days of the week.

\footnotetext{
'The ratio of variances computed from the data in Table 9 is not directly comparable to the average variance ratios in Table 4 or Table 7 , although the results are fully consistent. First, the ratio of average variances is not equal to the average variance ratio. Second, the return variances are calculated for the entire data set for each stock, whereas in earlier tables variances were calculated month by month for each stock. Because we now require a variance estimate for each day of the week for each stock, the month-by-month procedure did not provide enough observations.
} 


\section{TABLE 9}

\section{Variance of Percentage Returns and $t$-statistics by Day of the Week}

\begin{tabular}{|c|c|c|c|c|c|}
\hline & Monday & Tuesday & Wednesday & Thursday & Friday \\
\hline Daytime variance & $\begin{array}{r}3.9984 \\
(59.235)\end{array}$ & $\begin{array}{l}4.0833 \\
(0.890)\end{array}$ & $\begin{array}{l}4.1412 \\
(1.496)\end{array}$ & $\begin{array}{r}4.0609 \\
(0.655)\end{array}$ & $\begin{array}{r}3.8927 \\
(-1.107)\end{array}$ \\
\hline Nighttime variance & $\begin{array}{r}1.4725 \\
(39.229)\end{array}$ & $\begin{array}{r}1.1766 \\
(-5.574)\end{array}$ & $\begin{array}{r}1.1364 \\
(-6.331)\end{array}$ & $\begin{array}{r}1.1605 \\
(-5.877)\end{array}$ & $\begin{array}{r}1.1344 \\
(-6.370)\end{array}$ \\
\hline Open-to-open variance & $\begin{array}{r}5.3679 \\
(57.479)\end{array}$ & $\begin{array}{r}5.3473 \\
(-0.156)\end{array}$ & $\begin{array}{r}5.3477 \\
(-0.153)\end{array}$ & $\begin{array}{r}5.4945 \\
(0.9580)\end{array}$ & $\begin{array}{r}5.3217 \\
(-0.3500)\end{array}$ \\
\hline Close-to-close variance & $\begin{array}{r}5.1263 \\
(60.339)\end{array}$ & $\begin{array}{r}4.9423 \\
(-1.531)\end{array}$ & $\begin{array}{r}4.9879 \\
(-1.151)\end{array}$ & $\begin{array}{r}4.9998 \\
(-1.053)\end{array}$ & $\begin{array}{r}4.7536 \\
(-3.102)\end{array}$ \\
\hline Number of stocks & 1,788 & 1,788 & 1,788 & 1,788 & 1,788 \\
\hline
\end{tabular}

Day-of-the-week effects are estimated in a regression equation of the following form:

$$
y=a_{0}+a_{1} T u+a_{2} W e+a_{3} T h+a_{4} F r+e,
$$

where $y$ is the variable of interest, such as daytime variance, and $T u, W e, T h$, and $F r$ each take on the value one if the observation is for the indicated day and zero otherwise. The unit of observation is the variance for a stock based on observations for the given day. The value in the table for Monday is â, and the $t$-statistic for Monday tests the null hypothesis that the Monday mean is zero. The value in the table for the other days is the intercept plus the estimated coefficient for that day, and the $t$ values for the remaining days test the null that the difference from Monday is zero. Parentheses indicate $t$-statistics.

These results provide insights into the sources of volatility if one is willing to make some assumptions about the arrival of public information. If the public information arriving over a 66 -hour weekend period exceeds by more than 28 percent the public information during other nighttimes and is not 62 percent less than the amount of public information arriving on Monday, the observed volatility during trading hours is the result of not only public information, but also private information revealed through trading, and the noise induced by liquidity traders. 


\section{Patterns in Serial Covariances and Implied Spreads}

We have shown that open-to-open returns tend to have a greater negative serial correlation than close-to-close returns, and that the correlation between the daytime and the following overnight return, $\rho\left(r_{d, t-1}, r_{n, t}\right)$, exceeds the correlation between the overnight and the following daytime return, $\rho\left(r_{n, t}, r_{d, t}\right)$. Table 10 shows the day-of-the-week pattern in the serial covariance of returns, and Table 11 shows the day-of-the-week pattern in the bid-ask spreads implied by the serial covariances. The results are consistent with our earlier findings, although our estimation procedures are different: one serial covariance is

\section{TABLE 10}

\section{Serial Covariance of Percentage Returns and $t$-statistics by Day of the Week}

$\begin{array}{lrrrrr} & \text { Monday } & \text { Tuesday } & \text { Wednesday } & \text { Thursday } & \text { Friday } \\ & & & & & \\ \operatorname{cov}\left(r_{n, t}, r_{d, t}\right) & -0.1714 & -0.1583 & -0.1445 & -0.1106 & -0.1365 \\ & (-16.675) & (0.898) & (1.850) & (4.183) & (2.403) \\ \operatorname{cov}\left(r_{d, t-1}, r_{n, t}\right) & -0.0148 & 0.0681 & 0.0625 & 0.0896 & 0.0586 \\ & (-1.338) & (5.305) & (4.946) & (6.683) & (4.6930) \\ \operatorname{cov}\left(r_{o, t-1}, r_{0, t}\right) & 0.0696 & -0.0228 & -0.1297 & -0.0326 & 0.0486 \\ & (2.888) & (-2.712) & (-5.851) & (-3.001) & (-0.616) \\ \operatorname{cov}\left(r_{c, t-1}, r_{c, t}\right) & 0.1593 & 0.1548 & 0.1864 & 0.2602 & 0.2757 \\ & (7.693) & (-0.154) & (0.925) & (3.448) & (3.977) \\ & & & & & \\ \text { Number of stocks } & 1,788 & 1,788 & 1,788 & 1,788 & 1,788\end{array}$

Day-of-the-week effects are estimated in a regression equation of the following form:

$$
y=a_{0}+a_{1} T u+a_{2} W e+a_{3} T h+a_{4} F r+e,
$$

where $y$ is the variable of interest, such as $\operatorname{cov}\left(r_{n, t}, r_{d, t}\right)$, and $T u, W e, T h$, and $F r$ each take on the value one if the observation is for the indicated day and zero otherwise. The unit of observation is the covariance for a stock based on adjacent observations for the given day. The value in the table for Monday is â and the $t$-statistic for Monday tests the null hypothesis that the Monday mean is zero. The value in the table for the other days is the intercept plus the estimated coefficient for that day, and the $t$ values for the remaining days test the null that the difference from Monday is zero. Parentheses indicate $t$-statistics. 


\section{TABLE 11}

\section{Implied Bid-Ask Spreads by Day of the Week}

$\begin{array}{lrrrrr} & \text { Monday } & \text { Tuesday } & \text { Wednesday } & \text { Thursday } & \text { Friday } \\ & & & & & \\ \left(r_{n, t}, r_{d, t}\right) & 0.8280 & 0.7959 & 0.7603 & 0.6651 & 0.7388 \\ \left(r_{d, t-1,}, r_{n, t}\right) & 0.2432 & -0.5220 & -0.5000 & -0.5988 & -0.4840 \\ \left(r_{\left.o, t-1, r_{o, t}\right)}\right. & -0.5275 & 0.3020 & 0.7203 & 0.3614 & -0.4409 \\ \left(r_{\left.c, t-1, r_{c, t}\right)}\right. & -0.7982 & -0.7868 & -0.8634 & -1.0202 & -1.0501 \\ \text { Number of stocks } & 1,788 & 1,788 & 1,788 & 1,788 & 1,788\end{array}$

Implied bid-ask spreads are calculated as $2 \sqrt{- \text { cov }}$ from covariance estimates reported in Table 10. If the covariance is positive, the negative sign is carried outside the square root and a negative spread is reported.

estimated for each stock for each day of the week (previously serial covariances were estimated each month for each stock).

The most striking feature of Tables 10 and 11 is the consistent negative serial covariance between the nighttime and following daytime return $\left[\operatorname{cov}\left(r_{n, t}, r_{d, t}\right)\right]$, a result that corresponds to the uniformly negative serial correlation reported in Table 5 for this variable. These serial covariances (Table 10) range from -0.1714 on Monday to -0.1106 on Thursday. The implied spreads calculated according to the Roll (1984) procedure range from 0.8280 percent to 0.6651 percent. These results suggest that an opening price that deviates from the prior close tends to be reversed during the day. This pattern is consistent with the specialist earning profits by trading at the opening and offsetting his position during the day.

Slight positive serial covariance is present between the daytime return and the following nighttime return $\left[\operatorname{cov}\left(r_{d, t-1}, r_{n, t}\right)\right]$, except from Friday to Monday when the serial covariance is slightly negative. This may be attributable to reversals following stock index expiration days, which occur on Fridays. Typically, however, price trends seem to carry over to the next morning.

Close-to-close returns tend to be positively serially correlated on each day of the week, and open-to-open returns tend to be negatively serially correlated 
except on Monday and Friday. The uniform positive serial covariance in close-to-close returns (Table 10) differs from the findings in Table 5, where positive serial correlation is observed in three of the five volume categories. The results in Table 10 are sensitive to periods of time when all stocks experienced some strong positive serial covariance, which may explain the relatively strong positive serial covariance in close-to-close returns. 


\section{Volatility and Volume}

The evidence in the preceding chapter reveals several empirical regularities. First, the average ratio of the variance of open-to-open returns to the variance of close-to-close returns is greater than one and increases with the daily dollar-volume trading activity. On the basis of this evidence, the null hypothesis that trading shocks are smaller at the open than at the close is rejected.

Second, the serial dependence in open-to-open returns and between the overnight and following daytime return is negative in all volume categories, but is less negative in high-volume stocks than in low-volume stocks. This suggests that the suppliers of liquidity, who are compensated by price reversals, are responsible-at least in part-for the higher volatility of the opening, because their compensation is greater in low-volume stocks than in highvolume stocks.

Third, the serial dependence in close-to-close returns and between the daytime return and the following overnight return is positive in the three largest volume categories. This positive correlation suggests the presence of price momentum between the closing price and the next morning's open.

Fourth, the significantly higher volatility during the daytime than over a weekend or during the nighttime suggests that trading itself is an important source of volatility.

In this chapter, we first analyze how volatility of returns and serial dependence in returns are related to trading shocks. One would expect larger trading shocks to bring about larger return volatility, according to equation (2) and Figure 1. We proxy trading shocks by trading volume. Second, we test whether volatility associated with trading shocks is a result of higher compen- 
sation of the specialist or of greater trading activity by informed traders.

\section{Trading Volume and Price Volatility}

The relation between return in a stock and trading shocks is expressed by equation (2) in Chapter 1. As illustrated in Figure 1, the values of $u_{t}$ and $u_{t-1}$ depend on order imbalances at the beginning and ending points of the return interval. The direction and magnitude of these imbalances are not directly observable. Knowledge of the direction of imbalances, however, is not necessary in assessing their effect on volatility. Only the magnitude of the imbalance is required. A natural proxy for the order imbalance is the abnormal volume of shares traded. In U.S. markets, abnormally high trading volume usually indicates a trading imbalance because efficient procedures for bringing in the other side of a trade on short notice do not exist.

In addition to the presence of high volume at the open, another indication of an order imbalance is a delay in opening a stock. In actively traded stocks, such delays typically occur while the specialist seeks to round up the other side of the imbalance. In less actively traded stocks, a delayed open may simply mean the absence of any orders. Because of this, we analyze stocks classified into dollar-volume deciles.

Although equation (2) is most naturally applied to successive transactions, some returns, such as the daytime return, are defined over a time interval encompassing many transactions. An interesting issue to investigate is the extent to which through-put volume (that is, volume between the open and the close as opposed to volume at the open or at the close) is related to return volatility. If trading volume were due to liquidity trading, price effects would reflect the cost of supplying immediacy. In such a world, on the one hand, price changes tend to be fully reversed, in which case through-put volume is not related to return volatility. On the other hand, if volume were due to information trading, through-put volume would be related to return volatility because price changes would not tend to reverse.

\section{Overnight and Daytime Volatility}

To test the relation between volatility and trading shocks, we regress the volatility of overnight and daytime returns on proxies for trading shocks. In these regressions, volatility is measured by the absolute value of the return. ${ }^{1}$

\footnotetext{
${ }^{1}$ An alternative proxy for the return volatility is the square of return.
} 
Trading shocks are approximated by standardized volume or standardized time delay. Each observation for a stock is standardized by subtracting the mean for the stock in the month and dividing by the monthly standard deviation. Because we use share volume as a variable, we exclude days in which splits or stock dividends occurred. ${ }^{2}$

In the first regression [equation (7)], the absolute value of the overnight return is regressed on the following: $D_{t}$, a dummy variable taking the value one on Monday and zero on other days; $v_{c, t-1}$, the standardized share volume at the close on day $t-1 ; v_{o, t}$, the standardized share volume at the open on day $t$; and $\tau_{t}$, the standardized proportion of the trading day elapsed before the first trade occurs; that is,

$$
\left|r_{n, t}\right|=a_{0}+a_{1} D_{t}+a_{2} v_{c, t-1}+a_{3} v_{o, t}+a_{4} \tau_{t}+\varepsilon_{t} .
$$

Under the null hypothesis that order imbalances do not affect volatility, the coefficients $a_{2}, a_{3}$, and $a_{4}$ should equal zero. The coefficient $a_{1}$ is equal to zero under the null hypothesis that a close-to-open return spanning a weekend has the same volatility as an overnight return not spanning a weekend.

In the second regression, the absolute value of the daytime return is regressed on the following: the Monday dummy; standardized endpoint volumes, $v_{o, t}$ and $v_{c, t}$; standardized through-put volume, defined as standardized daily share volume not including the standardized endpoint volumes, $\omega_{t}$, where $\omega_{\mathrm{t}} \equiv v_{\mathrm{t}}-v_{o, t}-v_{c, t}$; and the standardized delay at the open, $\tau_{t}$. That is,

$$
\left|r_{d, t}\right|=a_{0}+a_{1} D_{t}+a_{2} v_{o, t}+a_{3} v_{c, t}+a_{4} \omega_{t}+a_{5} \tau_{t}+\varepsilon_{t} .
$$

The coefficients in equation (8) have the same interpretation as those in equation (7), with the exception of the coefficient on through-put volume, $a_{4}$. Under the null hypothesis, which states that imbalances do not have price effects, $a_{4}$ is zero; but it is also zero if imbalances have price effects that are reversed during the day. A nonzero value of $a_{4}$ implies the presence of informed traders who convey information by trading.

The regressions in equations (7) and (8) are performed on daily data for individual stocks that are classified each month into 10 groups according to

\footnotetext{
${ }^{2}$ We could use dollar volume, but on ex-dividend days that might induce spurious correlation with our dependent variable.
} 
average daily dollar volume of trading in the month. ${ }^{3}$ The results are contained in Table 12.

Panel 1 of Table 12 focuses on the overnight return that ends with the opening price, and Panel 2 focuses on the daytime return that ends with the closing price. As expected, the overnight return ending with the Monday opening price is more volatile than other overnight returns during the week: 0.129 percent more in the case of the highest dollar-volume stocks. This difference in volatility, however, is not proportional to the greater time elapsed. The daytime return on Monday also exhibits slightly higher volatility than on other days, but the effect is small and of marginal statistical significance given the large number of observations.

Overnight return volatility is strongly related to abnormal volume at the open, $v_{o, t}$, with $t$-values exceeding 50 in all volume categories. In the largest volume category, a standard deviation increase of 1.0 in opening volume is related to a volatility increase of 0.192 percent. The effect of an increase in time to opening, $\tau_{t}$, may be interpreted differently depending on the volume category of the stock. Among high-volume stocks, an increase in the time to opening is likely to reflect difficulty in opening the stock. As a result, a delay in opening has a strong positive association with overnight volatility: A standard deviation increase of 1.0 in the time to open is associated with an increase of 0.235 percent in overnight volatility. Among low-volume stocks, an increase in time to opening signifies inactivity and is associated with reduced volatility.

Daytime volatility is also strongly related to opening volume, and the coefficient is somewhat larger than in the overnight-volatility regression. This implies that trading pressures at the open have lasting effects on volatility. Interestingly, the opening time delay, after accounting for opening volume, is not associated with increased volatility during the rest of the day. This implies that delayed openings are successful in establishing fair prices. ${ }^{4}$ Through-put volume during the day, $\omega_{t}$, and closing volume, $v_{c t}$, also are significantly related to daytime volatility; the magnitudes of all the volume coefficients are about

\footnotetext{
${ }^{3}$ The monthly dollar volume of each stock is also included as an independent variable to provide an additional control. The coefficient values are not reported for this variable.

${ }^{4}$ In the low-volume categories, time delay is associated with reduced volatility during the rest of the day, but this simply reflects inactivity in those stocks.
} 


\section{TABLE 12}

\section{Results of Time-Series, Cross-Sectional Regressions of Overnight Return Volatility $\left|r_{n, t}\right|$ and Daytime Return Volatility $\left|r_{d, t}\right|$ on Trading Volume and Delayed Openings}

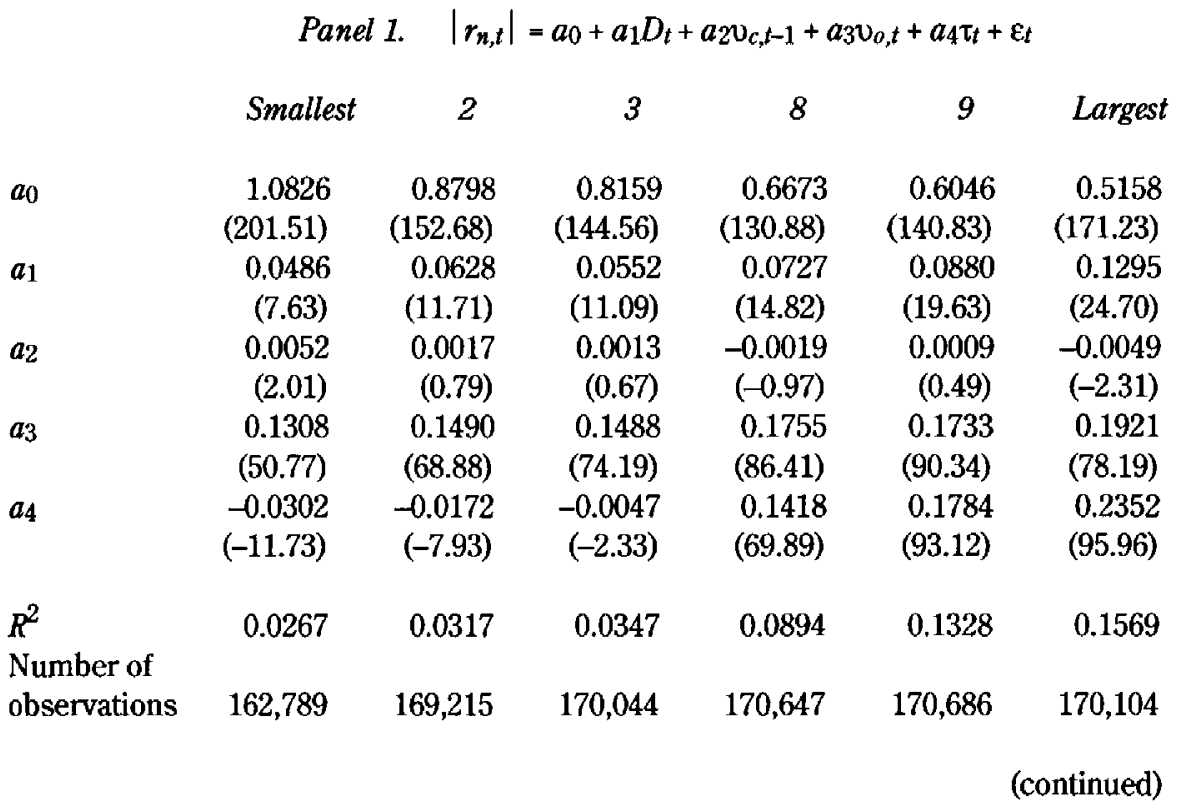

the same in the daytime regression. The significance of the through-put volume, in particular, suggests the existence of price effects that are not reversed and implies the presence of information trading.

The results in Table 12 provide additional support for the proposition that market structure affects volatility. The influence of trading volume at the open is quite strong. ${ }^{5}$ This suggests an inability or unwillingness to find offsetting volume to mitigate opening-price volatility. The earlier finding that price changes at the open tend to be reversed, at least in part, implies that the

${ }^{5}$ Other studies find a relation between volume and volatility, but they do not examine volume at the open and close as compared with volume at other times of the day. See Karpoff (1987) for a survey of the evidence. 
TABLE 12 (Continued)

\section{Results of Time-Series, Cross-Sectional Regressions of Overnight Return Volatility $\left|r_{n, t}\right|$ and Daytime Return Volatility $\left|r_{d, t}\right|$ on Trading Volume and Delayed Openings}

\begin{tabular}{lrrrrrr}
\multicolumn{7}{c}{ Panel $2 . \quad\left|r_{d, t}\right|=a_{0}+a_{1} D_{t}+a_{2} v_{o, t}+a_{3} v_{c, t}+a_{4} \omega_{t}+a_{5} \tau_{t}+e_{t}$} \\
$a_{0}$ & 1.0557 & 1.1812 & 1.2089 & 1.3597 & 1.3722 & 1.2938 \\
& $(134.54)$ & $(121.79)$ & $(118.88)$ & $(159.12)$ & $(178.62)$ & $(289.02)$ \\
$a_{1}$ & 0.0260 & 0.0306 & 0.0381 & 0.0340 & 0.0521 & 0.0750 \\
& $(2.79)$ & $(3.39)$ & $(4.25)$ & $(4.12)$ & $(6.48)$ & $(9.61)$ \\
$a_{2}$ & 0.3451 & 0.3387 & 0.3217 & 0.2821 & 0.2878 & 0.2798 \\
& $(71.59)$ & $(73.93)$ & $(71.10)$ & $(66.78)$ & $(68.89)$ & $(65.73)$ \\
$a_{3}$ & 0.4750 & 0.4275 & 0.4049 & 0.3494 & 0.3632 & 0.4045 \\
& $(98.86)$ & $(90.10)$ & $(85.41)$ & $(78.18)$ & $(82.90)$ & $(93.73)$ \\
$a_{4}$ & 0.4657 & 0.4145 & 0.3817 & 0.3190 & 0.3275 & 0.3637 \\
& $(106.17)$ & $(102.86)$ & $(97.00)$ & $(90.98)$ & $(94.77)$ & $(104.94)$ \\
$a_{5}$ & -0.1037 & -0.0675 & -0.0570 & -0.0085 & -0.0132 & -0.0134 \\
& $(-26.86)$ & $(-18.32)$ & $(-15.67)$ & $(-2.51)$ & $(-3.85)$ & $(-3.68)$ \\
\multirow{4}{*}{$R^{2}$} & & & & & & \\
Number of & 0.0911 & 0.0723 & 0.0627 & 0.0510 & 0.0566 & 0.0675 \\
observations & 162,789 & 169,215 & 170,044 & 170,647 & 170,686 & 170,104
\end{tabular}

Stocks are classified into 10 groups based on average monthly dollar volume of trading. Regression results for stocks falling into the three lowest volume and three highest volume groups are reported in this table. The notation used in this table is as follows:

$D_{t}=1$ if day $t$ is a Monday, 0 otherwise;

$r_{n, t} \equiv$ close-to-open return in percent;

$r_{d, t} \equiv$ open-to-close return in percent;

$v_{o, t} \equiv$ opening standardized share volume on day $t$,

$v_{c, t} \equiv$ closing standardized share volume on day $t$;

$v_{t} \equiv$ total standardized share volume for day $t$;

$\tau_{t} \equiv$ standardized minutes until first trade in day $t$ as a proportion of total minutes of trading in day $t$; and

$\omega_{t} \equiv v_{t}-v_{\theta, t}-v_{c, t}$

Standardized variables are computed by subtracting the stock's mean value in the month and dividing by the standard deviation for the month. Parentheses indicate $t$ statistics. 
volatility at openings is partly the result of the presence of liquidity trading and the need to compensate providers of immediacy. The relation between volume and volatility is also strong during the remainder of the day. Through-put volume has an association comparable in magnitude to the effect of endpoint volume, which implies that an important source of structural volatility is information trading. Taken together, these findings indicate that higher volatility during trading rather than nontrading periods is the result of information trading, the noise induced by liquidity traders, and the response of market-makers.

\section{Open-to-Open and Close-to-Close Volatility}

Having examined daytime and overnight volatility, we now investigate the difference between volatility based on the open-to-open return and volatility based on the close-to-close return. More specifically, we regress the difference in absolute value of the open-to-open return and that of the close-to-close return of the preceding day (i.e., $\left|r_{o, t}\right|-\left|r_{c, t-1}\right|$ ) on endpoint volume, through-put volume, and opening delays. That is,

$$
\begin{aligned}
& \left|r_{o, t}\right|-\left|r_{c, t-1}\right|=a_{0}+a_{1} D_{t}+a_{2} v_{c, t-2}+a_{3} v_{o, t-1}+a_{4} v_{c, t-1} \\
& +a_{5} v_{a, t}+a_{6} \omega_{t-1}+a_{7} \tau_{t}+a_{8} \tau_{t-1}+\varepsilon_{t}
\end{aligned}
$$

The results, reported in Table 13, are consistent with those in Table 12. The variables that increase overnight volatility, opening volume, and time delay at the open, also increase the volatility of open-to-open returns as compared to close-to-close returns. The variables that increase daytime volatility, daytime volume, and closing volume, decrease the volatility of open-to-open returns as compared to close-to-close returns. The fact that lagged values of opening volume and of time delay enter with a negative sign indicates that changes in these variables are related to increased volatility.

Table 14 reports results of a comparable regression for the difference between absolute daytime and absolute overnight returns. These results are consistent with the results in Table 12 . Although normal daytime volatility exceeds normal overnight volatility as reflected in the intercept term, abnormally high volume during day $t$ or at the close of day $t$ substantially raises daytime relative to overnight volatility. Abnormal opening volume increases both overnight and daytime volatility, and it has a smaller net effect on the difference. The difference in volatilities is reduced by abnormal opening 


\section{TABLE 13}

\section{Results of Time-Series, Cross-Sectional Regressions of the Difference Between Open-to-Open Return Volatility $\left|r_{o, t}\right|$ and Close-to-Close Return Volatility from the Previous Day $\left|r_{c, t-1}\right|$ on Trading Volume and Delayed Openings}

\begin{tabular}{|c|c|c|c|c|c|c|}
\hline & Smallest & 2 & 3 & 8 & 9 & Largest \\
\hline$a_{0}$ & $\begin{array}{c}-0.0383 \\
(-3.43)\end{array}$ & $\begin{array}{c}-0.0238 \\
(-1.75)\end{array}$ & $\begin{array}{l}-0.0144 \\
(-0.107)\end{array}$ & $\begin{array}{r}-0.0020 \\
(-0.16)\end{array}$ & $\begin{array}{r}0.0278 \\
(2.91)\end{array}$ & $\begin{array}{r}0.0217 \\
(3.63)\end{array}$ \\
\hline$a_{1}$ & $\begin{array}{r}0.0739 \\
(5.58)\end{array}$ & $\begin{array}{r}0.0714 \\
(5.62)\end{array}$ & $\begin{array}{r}0.0719 \\
(6.02)\end{array}$ & $\begin{array}{r}0.1005 \\
(8.62)\end{array}$ & $\begin{array}{r}0.0682 \\
(6.86)\end{array}$ & $\begin{array}{r}0.0913 \\
(8.76)\end{array}$ \\
\hline$a_{2}$ & $\begin{array}{r}-0.0079 \\
(-1.47)\end{array}$ & $\begin{array}{r}-0.0029 \\
(-0.57)\end{array}$ & $\begin{array}{r}-0.0164 \\
(-3.40)\end{array}$ & $\begin{array}{r}-0.0121 \\
(-2.57)\end{array}$ & $\begin{array}{r}-0.0108 \\
(-2.69)\end{array}$ & $\begin{array}{r}-0.0060 \\
(-1.44)\end{array}$ \\
\hline$a_{3}$ & $\begin{array}{l}-0.0713 \\
(-10.37)\end{array}$ & $\begin{array}{r}-0.0641 \\
(-9.92)\end{array}$ & $\begin{array}{l}-0.0706 \\
(-11.70)\end{array}$ & $\begin{array}{l}-0.0905 \\
(-15.12)\end{array}$ & $\begin{array}{l}-0.0937 \\
(-18.08)\end{array}$ & $\begin{array}{r}-0.1291 \\
(-22.63)\end{array}$ \\
\hline$a_{4}$ & $\begin{array}{r}-0.0585 \\
(-8.52)\end{array}$ & $\begin{array}{r}-0.0419 \\
(-6.26)\end{array}$ & $\begin{array}{c}-0.0455 \\
(-7.17)\end{array}$ & $\begin{array}{r}-0.0535 \\
(-8.41)\end{array}$ & $\begin{array}{l}-0.0628 \\
(-11.52)\end{array}$ & $\begin{array}{r}-0.1086 \\
(-18.65)\end{array}$ \\
\hline$\alpha_{5}$ & $\begin{array}{r}0.1306 \\
(24.34)\end{array}$ & $\begin{array}{r}0.1265 \\
(24.65)\end{array}$ & $\begin{array}{r}0.1255 \\
(26.01)\end{array}$ & $\begin{array}{r}0.1319 \\
(27.19)\end{array}$ & $\begin{array}{c}0.1358 \\
(31.70)\end{array}$ & $\begin{array}{r}0.1441 \\
(29.22)\end{array}$ \\
\hline$a_{6}$ & $\begin{array}{r}-0.0404 \\
(-6.45)\end{array}$ & $\begin{array}{r}-0.0315 \\
(-5.53)\end{array}$ & $\begin{array}{r}-0.0331 \\
(-6.29)\end{array}$ & $\begin{array}{r}-0.0342 \\
(-6.86)\end{array}$ & $\begin{array}{r}-0.0433 \\
(-10.05)\end{array}$ & $\begin{array}{c}-0.0823 \\
(-17.59)\end{array}$ \\
\hline$a_{7}$ & $\begin{array}{r}0.0011 \\
(0.20)\end{array}$ & $\begin{array}{r}-0.0014 \\
(-0.27)\end{array}$ & $\begin{array}{r}0.0205 \\
(4.26)\end{array}$ & $\begin{array}{r}0.1346 \\
(27.91)\end{array}$ & $\begin{array}{c}0.1618 \\
(38.05)\end{array}$ & $\begin{array}{r}0.2085 \\
(42.76)\end{array}$ \\
\hline$a_{8}$ & $\begin{array}{r}-0.0197 \\
(-3.58)\end{array}$ & $\begin{array}{r}-0.0085 \\
(-1.64)\end{array}$ & $\begin{array}{c}-0.0186 \\
(-3.84)\end{array}$ & $\begin{array}{l}-0.0604 \\
(-12.51)\end{array}$ & $\begin{array}{l}-0.0765 \\
(-17.98)\end{array}$ & $\begin{array}{r}-0.1003 \\
(-20.58)\end{array}$ \\
\hline$R^{2}$ & 0.0047 & 0.0044 & 0.0052 & 0.0147 & 0.0263 & 0.0387 \\
\hline $\begin{array}{l}\text { Number of } \\
\text { observations }\end{array}$ & 162,789 & 169,215 & 170,044 & 170,647 & 170,686 & 170,104 \\
\hline
\end{tabular}

Stocks are classified into 10 groups based on average monthly dollar volume of trading. Regression results for stocks falling into the three lowest-volume and three highest-volume groups are reported in this table. See Table 12 for definition of variables. Parentheses indicate $t$-statistics. 


\section{TABLE 14}

\section{Results of Time-Series, Cross-Sectional Regressions of the Difference Between Daytime Return Volatility $\left|r_{d, t}\right|$ and Return Volatility on the Preceding Night $\left|r_{n, t}\right|$ on Trading Volume and Delayed Openings}

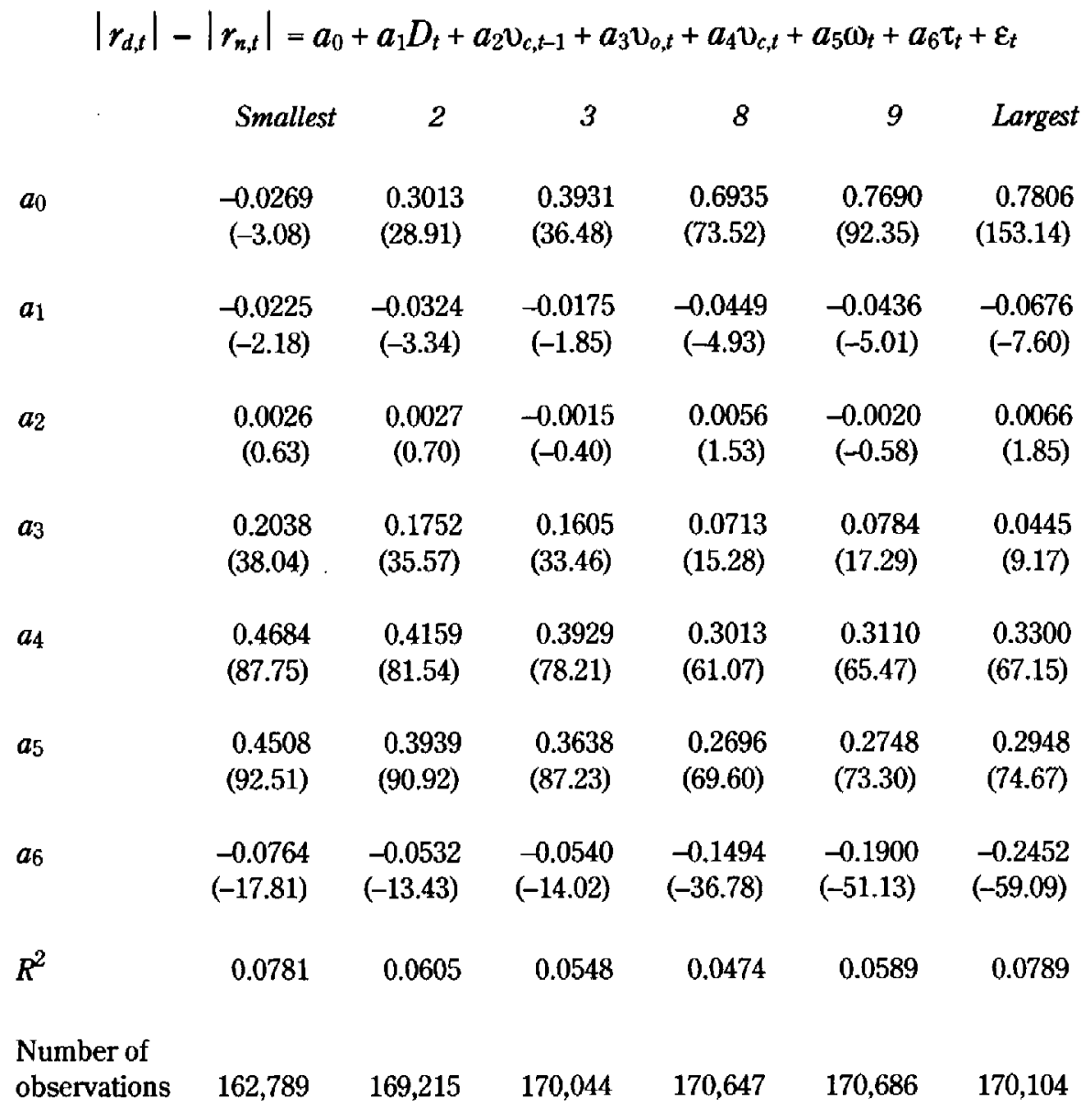

Stocks are classified into 10 groups based on average monthly dollar volume of trading. Regression results for stocks falling into the three lowest-volume and three highest-volume groups are reported in this table. See Table 12 for definition of variables. Parentheses indicate $t$-statistics. 
delays. In the high-volume stocks such delays are related to increases in overnight volatility without increases in daytime volatility.

On the basis of the regression results, we strongly reject the idea that order imbalances, using volume and delays in opening as proxies, are not related to volatility. Overnight volatility is strongly related to opening volume and delays in opening a stock. Daytime volatility is strongly related to volume at the open, at the close, and during the day. The difference between open-to-open volatility and close-to-close volatility reflects these same factors. Increases in opening volume and increases in time delays at the open result in more open-to-open volatility relative to close-to-close volatility. Larger daytime volumes decrease open-to-open volatility relative to close-to-close volatility. Because through-put volume during the day is significantly related to daytime volatility, price changes during the day are not fully reversed. In turn, this implies that volume is, at least in part, associated with information trading.

\section{Transaction Volume and Price Reversals}

The empirical results do not indicate whether the observed association between trading shocks and volatility arises from the greater costs of providing immediacy to liquidity traders when volume is high or solely from the presence of information trading. In this section, we perform tests to help distinguish between these sources of volatility.

Providers of immediacy, such as the specialist, are compensated by price reversals. The specialist tends to be passive, buying when others are selling and selling when others are buying. If the specialist is to make money, prices must recover after they have fallen, and they must fall after they have risen. We investigate whether the reversals documented earlier are related to volume of trading and opening delays.

The first-order serial dependence between the overnight return, $r_{n, t}$, and the daytime return, $r_{d, t}$, may be measured using the regression equation

$$
r_{d, t}=a_{o}+\alpha r_{n, t}+\varepsilon_{t} .
$$

The results in the first panel of Table 5 indicate that the estimated value of $\alpha$ is negative, which means that reversals do occur. To investigate whether the magnitude of the reversal as measured by $\alpha$ is related to endpoint volume, through-put volume, and opening delays, the following linear form is assumed:

$$
\alpha=a_{1}+a_{2} D_{t}+a_{3} v_{c, t-1}+a_{4} v_{o, t}+a_{5} v_{c, t}+a_{6} \omega_{t}+a_{7} \tau_{t}
$$


Substituting for $\alpha$ in equation (10) gives a regression equation with multiplicate independent variables, the results for which are reported in Table 15.

Consistent with the first panel of Table 5 , the coefficient $a_{1}$ is significantly negative in all volume categories of Table 15 , which indicates that providers of immediacy are being compensated. The decrease in the absolute magnitude of the coefficient as dollar trading volume increases probably reflects the smoothing effect of the large number of transactions in high-volume stocks. In low-volume stocks, we are more likely to observe successive transactions. In high-volume stocks, the daytime return spans many transactions, which attenuates the transaction-by-transaction reversals observed in the low-volume category. ${ }^{6}$

If high volume at the open or delayed openings were to accentuate reversals, the signs of $a_{4}$ and $a_{7}$ would be negative, but such is not the case. Instead, high volume at the open is associated with a price continuation. ${ }^{7}$ When the overnight return is positive on large opening volume, the subsequent daytime return also tends to be positive, holding volume constant during the rest of the day. On the other hand, when the overnight return is positive on low volume at the open (that is, standardized opening volume is negative), the subsequent daytime return tends to be negative, holding volume constant during the rest of the day. Similarly, below-average volume during the rest of the day is associated with a reversal of the overnight return. These results suggest that successive periods of high volume are associated with price continuations, whereas alternating high- and low-volume periods are associated with price reversals. A period of low volume appears to give the specialist the opportunity to reverse a position. On average, volume at the open is negatively correlated with volume the rest of the day, ${ }^{8}$ which is consistent with price reversals around the open.

\footnotetext{
${ }^{6}$ Stoll and Whaley (1990) find for S\&P 500 and non-S\&P 500 stocks nearly identical serial correlation coefficients of -0.238 and -0.183 , respectively, when the overnight return is regressed on the return in the last half-hour of the preceding day, for a sample of 11 days.

${ }^{7}$ The significant positive coefficients for multiplicate variables that include volume on day $t$ may also reflect the association of return (not absolute return) and volume that has been observed by others. See Mulherin and Gerety (1989).

${ }^{8}$ In other words, volume tends to be shifted. In a study of the Japanese stock market, Barclay, Litzenberger, and Warner (1988) also find that Saturday trading simply shifts volume from the rest of the week.
} 


\section{TABLE 15}

\section{Results of Time-Series, Cross-Sectional Regressions of Daytime Return on Preceding Overnight Return, Trading Volume, and Delayed Openings}

\begin{tabular}{|c|c|c|c|c|c|c|}
\hline \multicolumn{7}{|c|}{$\begin{aligned} r_{d, t}=a_{0}+a_{1} r_{n, t}+ & a_{2} r_{n, t} D_{t}+a_{3} r_{n, t} v_{c, t-1}+a_{4} \\
& +a_{6} r_{n, t}\left(\omega_{t}+a_{7} r_{n, t} \tau_{t}+\varepsilon_{t}\right.\end{aligned}$} \\
\hline & Smallest & 2 & 3 & 8 & 9 & Largest \\
\hline$a_{0}$ & $\begin{array}{r}-0.0120 \\
(-1.21)\end{array}$ & $\begin{array}{r}-0.0305 \\
(-2.38)\end{array}$ & $\begin{array}{r}-0.0681 \\
(-5.00)\end{array}$ & $\begin{array}{r}-0.0068 \\
(-0.57)\end{array}$ & $\begin{array}{r}-0.0063 \\
(-0.59)\end{array}$ & $\begin{array}{r}0.0327 \\
(5.34)\end{array}$ \\
\hline$a_{1}$ & $\begin{array}{l}-0.2286 \\
(-57.24)\end{array}$ & $\begin{array}{l}-0.2132 \\
(-45.03)\end{array}$ & $\begin{array}{l}-0.1977 \\
(-38.30)\end{array}$ & $\begin{array}{r}-0.0639 \\
(-9.84)\end{array}$ & $\begin{array}{r}-0.0369 \\
(-5.52)\end{array}$ & $\begin{array}{r}-0.0538 \\
(-7.97)\end{array}$ \\
\hline$a_{2}$ & $\begin{array}{r}0.0061 \\
(0.70)\end{array}$ & $\begin{array}{r}0.0115 \\
(1.15)\end{array}$ & $\begin{array}{r}0.0502 \\
(4.61)\end{array}$ & $\begin{array}{r}0.0010 \\
(0.09)\end{array}$ & $\begin{array}{r}-0.0418 \\
(-3.74)\end{array}$ & $\begin{array}{r}-0.0702 \\
(-7.47)\end{array}$ \\
\hline$a_{3}$ & $\begin{array}{r}-0.0003 \\
(-0.07)\end{array}$ & $\begin{array}{r}0.0083 \\
(2.01)\end{array}$ & $\begin{array}{r}0.0212 \\
(4.67)\end{array}$ & $\begin{array}{r}0.0007 \\
(0.14)\end{array}$ & $\begin{array}{r}0.0004 \\
(0.08)\end{array}$ & $\begin{array}{r}-0.0088 \\
(-2.09)\end{array}$ \\
\hline$a_{4}$ & $\begin{array}{r}0.0830 \\
(22.56)\end{array}$ & $\begin{array}{c}0.1156 \\
(30.67)\end{array}$ & $\begin{array}{r}0.1122 \\
(28.01)\end{array}$ & $\begin{array}{r}0.0310 \\
(7.79)\end{array}$ & $\begin{array}{r}0.0179 \\
(3.89)\end{array}$ & $\begin{array}{r}0.0239 \\
(5.70)\end{array}$ \\
\hline$a_{5}$ & $\begin{array}{r}0.0933 \\
(20.79)\end{array}$ & $\begin{array}{r}0.1187 \\
(22.49)\end{array}$ & $\begin{array}{r}0.1339 \\
(22.99)\end{array}$ & $\begin{array}{r}0.1290 \\
(22.02)\end{array}$ & $\begin{array}{r}0.1294 \\
(21.71)\end{array}$ & $\begin{array}{r}0.0958 \\
(18.74)\end{array}$ \\
\hline$a_{6}$ & $\begin{array}{r}0.0987 \\
(25.24)\end{array}$ & $\begin{array}{r}0.1472 \\
(34.23)\end{array}$ & $\begin{array}{r}0.1552 \\
(34.27)\end{array}$ & $\begin{array}{r}0.1080 \\
(24.03)\end{array}$ & $\begin{array}{r}0.1186 \\
(26.01)\end{array}$ & $\begin{array}{r}0.0978 \\
(22,89)\end{array}$ \\
\hline$a_{7}$ & $\begin{array}{r}0.0556 \\
(15.34)\end{array}$ & $\begin{array}{r}0.0329 \\
(8.13)\end{array}$ & $\begin{array}{r}0.0215 \\
(4.85)\end{array}$ & $\begin{array}{r}-0.0007 \\
(-0.18)\end{array}$ & $\begin{array}{r}0.0201 \\
(5.09)\end{array}$ & $\begin{array}{r}0.0086 \\
(2.30)\end{array}$ \\
\hline$R^{2}$ & 0.0284 & 0.0205 & 0.0163 & 0.0052 & 0.0056 & 0.0051 \\
\hline $\begin{array}{l}\text { Number of } \\
\text { pbservations }\end{array}$ & 162,789 & 169,215 & 170,044 & 170,647 & 170,686 & 170,104 \\
\hline
\end{tabular}

Stocks are classified into 10 groups based on average monthly dollar volume of trading. Regression results for stocks falling into the three lowest-volume and three highest-volume groups are reported in this table. See Table 12 for definition of variables. Parentheses indicate $t$-statistics. 


\section{TABLE 16}

\section{Results of Regressions of Overnight Return on Preceding Daytime Return, Trading Volume, and Delayed Openings}

$$
\begin{gathered}
r_{n, t}=a_{0}+a_{1} r_{d, t-1}+a_{2} r_{d, t-1} D_{t}+a_{3} r_{d, t-1} v_{o, t-1} \\
+a_{4} r_{d, t-1} v_{c, t-1}+a_{5} r_{d, t-1} v_{o, t}+a_{6} r_{d, t-1} \omega_{t-1} \\
+a_{7} r_{d, t-1} \tau_{t-1}+a_{8} r_{d, t-1} \tau_{t}+\varepsilon_{t}
\end{gathered}
$$

$\begin{array}{lllllll}\text { Smallest } & 2 & 3 & 8 & 9 & \text { Largest }\end{array}$

$\begin{array}{lrrrrrr}a_{0} & -0.0973 & -0.0508 & -0.0144 & 0.0009 & 0.0067 & 0.0258 \\ & (-13.90) & (-6.68) & (-1.93) & (0.14) & (1.25) & (7.46) \\ a_{1} & -0.1046 & -0.0499 & -0.0255 & 0.0319 & 0.0455 & 0.0621 \\ & (-51.09) & (-29.59) & (-16.40) & (21.18) & (31.87) & (38.18) \\ a_{2} & -0.0154 & -0.0190 & -0.0276 & -0.0182 & -0.0227 & -0.0337 \\ & (-3.62) & (-5.28) & (-8.18) & (-5.50) & (-7.17) & (-9.46) \\ a_{3} & 0.0176 & 0.0184 & 0.0116 & -0.0071 & -0.0143 & -0.0307 \\ & (8.94) & (11.65) & (7.74) & (-4.71) & (-9.64) & (-17.49) \\ a_{4} & 0.0137 & 0.0063 & 0.0006 & -0.0215 & -0.0337 & -0.0546 \\ & (7.76) & (3.87) & (0.38) & (-13.59) & (-22.71) & (-33.87) \\ a_{5} & 0.0480 & 0.0531 & 0.0579 & 0.0393 & 0.0379 & 0.0472 \\ & (29.73) & (43.05) & (51.13) & (33.92) & (32.89) & (33.08) \\ a_{6} & 0.0208 & 0.0122 & 0.0084 & -0.0064 & -0.0197 & -0.0379 \\ & (13.00) & (9.44) & (6.91) & (-5.41) & (-17.15) & (-28.35) \\ a_{7} & -0.0112 & -0.0049 & -0.0044 & 0.0007 & 0.0044 & -0.0001 \\ & (-5.30) & (-3.07) & (-3.02) & (0.54) & (3.29) & (-0.08) \\ a_{8} & -0.0160 & -0.0081 & 0.0048 & 0.0485 & 0.0601 & 0.0678 \\ & (-8.29) & (-4.98) & (3.18) & (37.37) & (48.58) & (45.12) \\ & 0.0249 & 0.0168 & 0.0179 & 0.0325 & 0.0521 & 0.0680 \\ R^{2} & & & & & & \end{array}$

Number of $\begin{array}{lllllll}\text { observations } & 162,789 & 169,215 & 170,044 & 170,647 & 170,686 & 170,104\end{array}$

Stocks are classified into 10 groups based on average monthly dollar volume of trading. Regression results for stocks falling into the three lowest-volume and three highest-volume groups are reported in this table. See Table 12 for definition of variables. Parentheses indicate $t$-statistics. 
Table 16 is similar to Table 15 , but it examines the serial correlation between the overnight return and the preceding day's return. In the three largest-volume categories, the important role of volume in reversals is evident. When opening volume, closing volume, or through-put volume on day $t-1$ is high, the opening price on day $t$ tends to reverse the return on day $t-1$ (holding opening volume and opening delay constant on day $t$ ). In the absence of above-normal volume on day $t-1$, the opening price tends to continue the preceding day's trend ( $a_{1}$ is positive), particularly if opening volume and delay in opening are above normal. If opening volume is below normal, the tendency to reverse the preceding day's return is accentuated. In Table 15, we noted a tendency for price continuations between the daytime and following overnight return among large stocks. The results in Table 16 help explain this tendency and indicate that continuations depend on the pattern of volume. When volume is low, its role in reversals is less evident, and the tendency for reversals is reflected in the intercept term.

The results in Tables 15 and 16 give insight into the sources of volatility at the open. Prices determined at the open when opening volume is above normal do not tend to be reversed (Table 15), although they are followed by greater volatility (Table 12). Prices determined at the open when opening volume is below normal tend to be reversed (Table 15). Prices determined during the day when volume during the day is above normal tend to be reversed at the next day's open, particularly if opening volume on the next day is below normal (Table 16). These results are consistent with a market mechanism in which the specialist liquidates positions at low-volume openings. At such times, the specialist may have more discretion in establishing a favorable price. In addition, it may be difficult to liquidate a position when opening volume is high because such occasions result in price continuations that force the specialist's inventory in the same direction as on the previous day. 


\section{Summary}

This study has investigated the structure of the market at the open of the NYSE. We devised an analytical framework for assessing the magnitude of structurally induced price volatility and applied it to price data for all NYSE common stocks during the period 1982 through 1986.

First, we described the timing of opening and closing trades in individual stocks. In 1986, for example, the average delay between exchange open and the first trade of the day was 15.48 minutes, and the average time between the last trade and the exchange close was 19.94 minutes. The volume of trading at the open was demonstrated to be substantial, accounting for about 19.5 minutes of trading in the highest-volume decile and about 128 minutes of trading in the lowest-volume decile. The most striking feature of these descriptive statistics was the relative infrequency of trading in many stocks. We found, moreover, that the distribution of volume and the timing of trading was about the same on all days of the week, but aggregate volume on Monday was less than on other days.

The ratio of open-to-open return variance to close-to-close return variance was significantly greater than one for the sample of stocks used in this study. The greater volatility at the open cannot be related to the way in which public information is released because both the open-to-open and close-to-close returns span the same period of time. The greater volatility at the open results either from the presence of private information revealed in trading or from the fortuitous nonsynchronization of liquidity trading that causes price changes and enables the suppliers of immediacy to earn revenues.

We found negative serial correlation of overnight and daytime returns, which implies that prices tend to reverse around the open. This indicates that 
suppliers of immediacy are extracting a premium for their services. The average implied spread across all stocks in the period 1982 to 1986 was 0.8983 percent if based on open-to-open returns, but only 0.0971 percent if based on close-to-close returns. Prices thus have a greater tendency to reverse around the open than around the close. Modifications in market structures may be able to eliminate such volatility.

Evidence of negative serial dependence is not inconsistent with the presence of informed trading because prices were not fully reversed. Most likely, some component of price changes is related to the presence of private information revealed through trading. Indeed, in the large-volume stocks, positive serial dependence has been observed.

Over the entire sample, daytime volatility was 5.4 times as large as overnight volatility. Weekend volatility of 66 hours was only 28 percent greater than nighttime volatility of 18 hours. These differences may be the result of a greater release of public information during the day than during the night or weekend, private information revealed through trading when the market is open, or the noise induced by liquidity traders and the response of suppliers of immediacy. Our evidence suggests that noise-as seen, for example, in reversals in the opening-and private information trading-as seen, for example, in the correlation between volume and volatility and the positive serial correlation around the close-are important sources of volatility.

Average returns of stocks during the 1982-86 period were significantly lower when the market was closed than when it was open, which is consistent with the lower volatility during these times.

In addition, average returns were negative from Friday close to Monday open and during the day on Monday, a result that is not consistent with efficient markets. Average returns were largest on Friday. Although return differences across days of the week are too small to arbitrage, one might expect buyers of stock to delay purchases until after Monday and sellers to pick the Friday close to sell. Investor patterns of buying and selling may induce the observed pattern of returns to draw forth the necessary market-making capital.

Serial covariances and implied bid-ask spreads are also examined by day of the week. The serial covariance between the nighttime and the following daytime return was consistently negative. These covariances ranged from -0.1714 on Monday to -0.1106 on Thursday. The implied spreads calculated according to the Roll (1984) procedure ranged from 0.8280 percent to 0.6651 percent. Our results suggest that an opening price that deviates from the prior 
close tends to be reversed during the day. Such a pattern is consistent with the specialist earning profits by trading at the opening and offsetting his position during the day.

We investigated in detail the extent to which volatility of the overnight return and of the daytime return are related to volume of trading and delays in opening a stock. We found that high volume at the open accentuates overnight return volatility and high volume during the rest of the day accentuates daytime volatility. The fact that volatility of the daytime return, which spans many transactions, is related to volume during the day indicates that volume has permanent effects on prices and, in turn, implies that private information is revealed through trading. In other words, higher daytime volatility is not solely attributable to the greater arrival of public information, but also to the arrival of private information as revealed through trading.

Furthermore, we found that among high-volume stocks, delayed openings accentuate overnight return volatility. Interestingly, volatility during the rest of the day was not greater than normal, holding constant other factors such as volume. This suggests that the price determined in delayed openings is correct. Among low-volume stocks, a delay in opening meant that volume was less than normal. As a result, daytime volatility was lower the longer the time to the first transaction.

We also investigated the relation between price reversals and volume. The opening price was more likely to reverse the price change of the preceding day if the volume on the prior day was above normal and if the opening volume was below normal. One may interpret this to mean that openings on high volume are less under the control of the specialist than openings on low volume. Overnight returns on above-normal opening volume were more likely to be reversed during the rest of the day if daytime volume was below normal.

Demand-side factors play an important role in the pattern of prices. High volume tends to be associated with price continuations; that is, an overnight return based on high opening volume is likely to be of the same sign as the preceding day's daytime return. An overnight return on high opening volume tends not to be reversed during the rest of the day if volume during the rest of the day continues above normal.

The impact of stock market structure on the short-run volatility of stock prices is complex, and it is difficult to separate the volatility induced by demand-side factors from the volatility induced by the way stocks are opened. Nevertheless, documented behaviors such as greater volatility around the 
open, the effect of trading volume on volatility, and the greater return to suppliers of immediacy at the open make it desirable to investigate improvements in the structure of trading. 


\section{REFERENCES}

Admati, A. and P. Pfleiderer, 1988. "A Theory of Intraday Patterns: Volume and Price Variability." Review of Financial Studies 1 (Spring): 3-40.

Amihud, Y. and H. Mendelson. 1987, "Trading Mechanisms and Stock Returns: An Empirical Investigation." Joumal of Finance 42 (July): 533-53.

Bagehot, W. (pseud.) 1971. "The Only Game in Town." Financial Analysts Joumal 27 (March/April): 12-14, 22.

Barclay, M., R. Litzenberger, and J. Warner. 1988. "Private Information, Trading Volume, and Stock Return Variances." Working Paper, University of Rochester (October).

Blume, M., C. MacKinlay, and B. Terker. 1989. “Order Imbalances and Stock Price Movements on October 19 and 20." Journal of Finance 44: 827-48.

Chopra V. 1990. "A Theory of Price Changes and Trading Volume." Working Paper, Owen School, Vanderbilt University (June).

Cohen, K, S. Maier, R. Schwartz, and D. Whitcomb. 1978. "The Return Generation Process, Returns Variance, and the Effect of Thinness in Securities Markets." Journal of Finance 33 (March): 149-67.

Demsetz, H. 1968. “The Cost of Transacting." Quarterly Journal of Economics 82 (February): 33-53.

Easley, D. and M. O'Hara. 1987. "Price, Trade Size and Information in Securities Markets." Journal of Financial Economics 19 (September): 69-90.

Foster, D. and S. Viswanathan. 1990. "A Theory of the Interday Variation in Volume, Variance, and Trading Costs in Securities Markets." Review of Financial Studies (forthcoming).

French, K 1980. "Stock Returns and the Weekend Effect." Joumal of Financial Economics 8 (March): 55-69. 
French, K. and R. Roll. 1986. "Stock Return Variances: The Arrival of Information and the Reaction of Traders." Journal of Financial Economics 17 (September): 5-26.

Gibbons, M. and P. Hess. 1981. "Day of the Week Effects and Asset Returns." Journal of Business 54 (October): $579-96$.

Glosten, L. and L. Harris. 1988. "Estimating the Components of the Bid-Ask Spread." Journal of Financial Economics 21: 123-42.

Goldman, B. and A. Beja. 1979. "Market Prices Versus Equilibrium Prices: Return's Variance, Serial Correlation, and the Role of the Specialist." Joumal of Finance 34 (June): 595-607.

Harris, L. 1986. "A Transaction Data Study of Weekly and Intradaily Patterns in Stock Returns.” Journal of Financial Economics 16 (May): 99-117.

Hasbrouck, J. 1988. "Trades, Quotes, Inventories and Information." Joumal of Financial Economics 22 (December): 229-52.

Hasbrouck, J. and T. Ho. 1987. "Order Arrival, Quote Behavior, and the Return Generating Process." Journal of Finance 42 (September): 1035-48.

Ho, T., R. Schwartz and D. Whitcomb. 1985. "The Trading Decision and Market Clearing Under Transaction Price Uncertainty." Joumal of Finance 40 (March): 21-42.

Karpoff, J. 1987. "The Relation Between Price Changes and Trading Volume: A Survey." Journal of Financial and Quantitative Analysis 22 (March): 109-26.

Keim, D. and R. Stambaugh. 1984. "A Further Investigation of the Weekend Effect in Stock Returns." Journal of Finance 39 (July): 819-40.

Kyle, A. 1985. "Continuous Auctions and Insider Trading." Econometrica 53 (November): $1315-35$.

Lakonishok, J. and E. Maberly. 1990. "The Weekend Effect: Trading Patterns of Individual and Institutional Investors." Journal of Finance 45 (March): 231-43. 
McInish, T. and R. Wood. 1989. "An Analysis of Intraday Patterns in Bid-Ask Spreads for NYSE Stocks." Working Paper, University of Texas at Arlington (March).

Mulherin, J. and M. Gerety. 1989. "Daily Trading Volume on the NYSE: An Empirical Analysis." Working Paper, Securities and Exchange Commission (April).

Oldfield, G. and R. Rogalski. 1980. "A Theory of Common Stock Returns OverTrading and Non-Trading Periods." Joumal of Finance 35 (June): 729-51.

Richardson, M. and T. Smith. 1988. "On Tests of Serial Dependency of Returns." Working Paper no. 88-117, Fuqua School of Business, Duke University.

Rogalski, R. 1984. "New Findings Regarding Day of the Week Returns Over'Trading and Non-Trading Periods." Joumal of Finance 39 (December): 1603-14.

Roll, R. 1984. "A Simple Implicit Measure of the Bid/Ask Spread in an Efficient Market." Joumal of Finance 39: 1127-39.

Stoll, H. 1978. "The Supply of Dealer Services in Securities Markets." Journal of Finance 33 (September): 1133-51.

_- . 1985. "The Stock Exchange Specialist System: An Economic Analysis." Monograph Series in Finance and Economics 1985-2, New York University.

—_ 1987. "Index Futures, Program Trading and Stock Market Procedures." Journal of Futures Markets 8 (August): 391-412.

. 1989. "Inferring the Components of the Bid-Ask Spread: Theory and Empirical Tests." Joumal of Finance 44 (March): 115-34.

Stoll, H. and A. Haller. 1989. "Market Structure and Transaction Costs: Implied Spreads in the German Stock Market." Journal of Banking and Finance 13 (September): $697-708$.

Stoll, H. and R. Whaley. 1987. "Program Trading and Expiration Effects." Financial Analysts Journal 43 (March/April): 16-28. 
Arbitrage, and Market Structure." Review of Futures Markets 7: 224-48.

_._ 1990a. "Program Trading and Individual Stock Returns: Ingredients of the Triple Witching Brew.” Journal of Business 63 (January): S165-92.

. 1990b. "Stock Market Structure and Volatility." Review of Financial Studies 3, No. 1: 37-71.

Wood, R., T. McInish, and J. K Ord. 1985. “An Investigation of Transaction Data for NYSE Stocks.” Journal of Finance 40 (July): 723-39. 